\title{
Fenómenos asociados a la estructura térmica superficial del mar observados a través de imágenes satelitales en la zona norte de Chile ${ }^{1}$
}

\author{
M.A. Barbieri B. ${ }^{2}$, M. Bravo R. ${ }^{3}$, M. Farías S. ${ }^{4}$, \\ A. González C., O. Pizarro A. y E. Yáñez R. \\ Escuela de Ciencias del Mar \\ Universidad Católica de Valparaíso \\ Casilla 1020, Valparaíso, Chile
}

\begin{abstract}
RESUMEN. Se emplean 1.867 imágenes satelitales de temperatura superficial del mar, para estudiar los fenómenos asociados a la estructura térmica en la zona norte de Chile $\left(18^{\circ} 21^{\prime}-24^{\circ} \mathrm{S}\right)$, entre 1987 y 1992 . Se observan enfriamientos costeros asociados a eventos de surgencia, los cuales se presentan normalmente en forma de focos, o bien, en bandas que cubren gran parte de la costa. Los eventos de surgencia por focos se observan durante todo el año en las siguientes localidades: punta Baquedano (18 $\left.35^{\prime} \mathrm{S}\right)$ (esporádica), punta Pichalo (19³5'S), entre punta Chucumata y punta Lobos $\left(20^{\circ} 31^{\prime} \mathrm{S}\right.$ a $\left.21^{\circ} 01^{\prime} \mathrm{S}\right)$, punta Arenas $\left(21^{\circ} 38^{\prime} \mathrm{S}\right)$ (esporádica y de menor intensidad) y en punta Angamos $\left(23^{\circ} 02^{\prime} \mathrm{S}\right)$. La intensidad de la surgencia es mayor en verano y menor en invierno, en tanto que la ubicación de los focos se mantiene durante todo el período de estudio. No se determinaron diferencias significativas en el número de eventos de surgencia entre zonas y entre años, con excepción de 1990. Cabe indicar que durante el período de estudio la zona se vio afectada por dos fenómenos El Niño, en 1987 y 1992.

Durante el verano los eventos de surgencia tienen una duración de 4 a 15 días, con una moda de 8 días. Estos son más frecuentes pero de menor duración en punta Baquedano, y de mayor duración en la punta Pichalo y al sur de Iquique (entre punta Chucumata y punta Lobos). La extensión de la lengua surgen te alcanza las $40 \mathrm{mn}$, con una moda de $30 \mathrm{mn}$ en el verano-otoño y $25 \mathrm{mn}$ en invierno-primavera. Los filamentos se forman preferentemente frente a punta Lobos y punta Arenas, con dirección NW y NWW; desde los bordes de la pluma surgente éstos alcanzan una longitud de 40-60 mn, es decir, 100-120 mn de la costa. En el sector de punta Angamos se observan filamentos durante todo el año, pero de menor extensión y con dirección norte. Se registra también la presencia de remolinos, principalmente al sur de punta Pichalo, y al norte de punta Gruesa $\left(20^{\circ} 20^{\prime} \mathrm{S}\right)$ y de Tocopilla $\left(22^{\circ} 05^{\prime} \mathrm{S}\right)$.
\end{abstract}

Palabras claves: temperatura superficial del mar, imágenes satelitales NOAA, surgencias, filamentos, remolinos, zona norte de Chile.

\section{Phenomena associated with the sea surface thermal structure observed through satellite images in the north of Chile}

SUMMARY. A total of 1,867 satellite images of sea surface temperature were used to study the thermal structure and

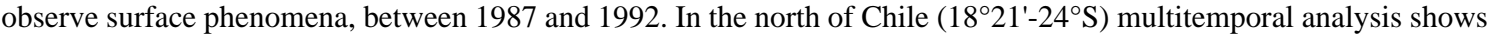
coolings associated to upwelling events, either by fringes or cells. The focal upwelling events may be observed all year round at five zones: punta Baquedano (18 $35^{\prime} \mathrm{S}$ ) (sporadic), punta Pichalo (19 $35^{\prime} \mathrm{S}$ ), between punta Chucumata and punta Lobos $\left(20^{\circ} 31^{\prime} \mathrm{S}\right.$ to $\left.21^{\circ} 01^{\prime} \mathrm{S}\right)$, punta Arenas $\left(21^{\circ} 38\right.$ 'S) (sporadic and of lower intensity) and in punta Angamos $\left(23^{\circ} 02^{\prime} \mathrm{S}\right)$. Upwelling intensity becomes greater in summer, and decreases towards the winter months. Location of this zones was permanent during the whole period of study, only altered by El Niño events (1987 and 1992).

During the summer months, upwelling events lasted from 4 to 15 days, with a mode of 8 days. They were more frecuent and of les ser duration in the area of punta Baquedano; of greater duration in the zones of punta Pichalo and Iquique. The extension of the upwelled tongue reaches around $40 \mathrm{~nm}$ with a mode of $30 \mathrm{~nm}$ in the summer-automm

${ }^{1}$ Proyectos FONDECYT N ${ }^{\circ} 0481-92$ y DGI-UCV N ${ }^{\circ} 223.749 / 93$.

${ }^{2}$ Dirección actual: Instituto de Fomento Pesquero, Huito 374, Valparaíso, Chile.

${ }^{3}$ Dirección actual: Servicio Hidrográfico y Oceanográfico de la Armada de Chile, Casilla 324, Valparaíso, Chile.

${ }^{4}$ Dirección actual: Pontificia Universidad Católica de Chile, Av. Vicuña Mackenna 4860, Santiago, Chile. 
season and $25 \mathrm{~nm}$ in the winter-spring season. Occasionally, injanuary and february, from the borders of the upwelling plume, filaments are formed towards the NW and NWW. They reach lengths of 40 to $60 \mathrm{~nm}$ preferently off punta Lobos and punta Arenas. These filaments were also observed in the sector of punta Angamos all year mund, bul directed towards the north and not as extense. In the areas south of Pisagua, lo the north of punta Gruesa $\left(20^{\circ} 20^{\prime} S\right)$ and to the north of Tocopilla $\left(22^{\circ} 05^{\prime} \mathrm{S}\right)$, the presence of eddies were also observed.

Key words: sea surface temperature, NOAA satellite images, upwellings, filaments, eddies, north of Chile.

\section{INTRODUCCION}

Los océanos presentan estructuras oceanográficas con una cierta variabilidad espacio-temporal, generalmente localizadas geográficamente, donde se relacionan con la forma de la costa (Crépon et al., 1984), la batimetría y los vientos. En la escala temporal de algunos días a decenas de días y en la espacial de algunos kilómetros a decenas de kilómetros, se producen eventos de surgencia. En la zona norte de Chile dichos eventos han sido señalados por diversos autores (Günther, 1936; Brandhorst, 1971; Robles et al., 1976; Cañón, 1978 y Fuenzalida, 1990). Estos eventos presentan una cierta repetitividad, la cual aprovechan los peces pelágicos para alimentarse y/o reproducirse (Herbland, 1991).

Los estudios de la surgencia en relación con las pesquerías son efectuados preferentemente con información obtenida de cruceros oceanográficos, o registrada en estaciones fijas tanto en la costa como en el océano (boyas). La información adquirida en cruceros, aunque más precisa, tiene la desventaja de ser puntual; mientras que los datos de estaciones fijas (de mareógrafos y meteorológicas) tienen la ventaja de tener una amplia cobertura temporal, pero demasiado global en el espacio. Dado lo anterior, se debe ser cuidadoso al dimensionar espacio-temporalmente el fenómeno o estructura que se desea estudiar. La observación del océano con satélites tiene la ventaja de dar una visión continua y sinóptica de amplias zonas; su resolución espacial y su cobertura han permitido revelar estructuras antes desconocidas.

El empleo de imágenes de temperatura superficial del mar (TSM), se ha difundido ampliamente en trabajos sobre estructuras térmicas superficiales de los océanos. Dentro de los más recientes, la variabilidad de la TSM en la zona común de pesca argentino-uruguaya (Pettigiani et al., 1992), los rasgos de estructuras térmicas (Holland y Van, 1992), los filamentos (Strub et al., 1992), los remolinos (Mitchelson, 1993), la surgencia (Van Camp et al.,
1991), y técnicas para reducir el efecto de la interferencia atmosférica como la neblina (Kudoh y Noguchi, 1991).

Mientras que en Chile se han empleado las imágenes de TSM en estudios de circulación superficial, surgencia y aplicación en pesquería (Espinoza et al., 1983; Barbieri et al., 1987, 1989; Fonseca y Farías, 1987; Acuña et al., 1989; Cáceres y Arcos, 1991; Cáceres, 1992). Recientemente, Yáñez et al. (1994) observan que en la zona norte de Chile la variabilidad de la TSM presenta patrones espaciotemporales bien definidos, particularmente en la franja costera donde se relaciona principalmente con los eventos de surgencia.

En el presente estudio se describen fenómenos y eventos que afectan la estructura de la TSM en la franja costera de la zona norte de Chile, entre 1987 y 1992. Para tal efecto se emplea información satelital de TSM de satélites NOAA y el viento medido en estaciones fijas en la costa. Se analiza con especial énfasis los eventos de la surgencia, estudiando su localización geográfica, ocurrencia e intensidad. Paralelamente, se discuten cartográficamente los eventos oceanográficos más sobresalientes, se determina una firma térmica de superficie y se efectúa un análisis estadístico para determinar la tipografía de la surgencia.

\section{MATERIALES Y METODOS}

\section{Información satelital}

Se empleó un total de 1.867 imágenes de TSM, que abarcaron un área de 565 por $410 \mathrm{~km}$ cada una, cubriendo la zona de estudio comprendida entre los $18^{\circ}$ y $23^{\circ} 30^{\prime} \mathrm{S}$, desde la costa hasta el meridiano $73^{\circ} \mathrm{W}$. Las imágenes fueron elaboradas con información proveniente del radiómetro A VHRR de satélites NOAA, que se adquirieron con el sistema HRPT. La adquisición y el procesamiento de los datos fue efectuado por el Centro de Estudios Espa- 
ciales (CEE) de la Universidad de Chile, que opera la estación de rastreo de Peldehue ubicada cerca de Santiago, Chile.

El sistema de tratamiento de imágenes fue diseñado para trabajar con computadores personales y programas desarrollados por el CEE y la Universidad Católica de Valparaíso (Barbieri et al., 1989). Además se utilizó el sistema de información geográfica IDRISI (Eastman, 1992).

Las imágenes se elaboraron con matrices de datos de TSM de 256 filas y 256 columnas, con una resolución espacial de $2,2 \mathrm{~km}$ en el sentido $\mathrm{N}-\mathrm{S}$ y de $1,6 \mathrm{~km}$ en el sentido E-W. A una escala de 1:2.000.000, la georreferencia de las imágenes se efectuó correferenciando la costa con el software denominado MUESTRE, para luego realizar un remuestreo con el software IDRISI.

\section{Tratamiento analógico y digital de imágenes satelitales}

El análisis de las imágenes implicó elaborar en primer lugar un catastro temático, efectuando una interpretación visual que consideró los siguientes aspectos: el color (que identifica valores de TSM utilizando pseudo-color), la estructura, la forma, el contorno (para el reconocimiento de los frentes), el patrón y la ubicación espacial (para el reconocimiento de filamentos, remolinos y otros). Al mismo tiempo se registró la cobertura de nubes y la TSM mínima, máxima y dominante, y se analizaron cartográficamente los eventos oceanográficos más sobresalientes (enfriamientos costeros, surgencias, remolinos y filamentos). Luego, a través de un tratamiento digital de las imágenes, se analizaron particularmente los eventos de surgencia, considerando tres características: localización geográfica, intensidad y frecuencia (periodicidad).

Posteriormente, las imágenes fueron clasificadas, tomando en cuenta el porcentaje de información utilizable en términos de registros de TSM no interferidos por nubes, empleando los siguientes criterios: buena (B) 71 al 100\%, regular (R) 31 al $70 \%$ y mala (M) 0 a 30\%. Por otra parte, desde el punto de vista espacial el área de estudio se dividió en 3 sectores: costero (entre la costa y los $71^{\circ} \mathrm{W}$ ), intermedio (entre $71^{\circ}$ y $72^{\circ} \mathrm{W}$ ) y oceánico (entre $72^{\circ}$ y $73^{\circ} \mathrm{W}$ ).

Luego se efectuó un análisis multitemporal de las imágenes diarias, para estudiar el dinamismo tem- poral de la zona de estudio y evaluar la superficie afectada por los fenómenos. Para estimar la extensión espacial de los enfriamientos costeros y de las surgencias, a través de los gradientes, se emplearon filtros espaciales utilizando operadores estadísticos de primer orden.

Para analizar los eventos de surgencia costera se consideró el empleo de filtros espaciales. La zona costera del área de estudio fue dividida en 120 subáreas de 4,4 km de latitud y de $16 \mathrm{~km}$ desde la línea de la costa hacia el oeste; previamente se probaron diversas extensiones y se escogió la que presentó una mayor amplitud. Después, con el programa MAPAS se estimó para cada imagen diaria disponible la TSM promedio (TSMP) de cada subárea.

Para describir el comportamiento espacio-temporal de la TSMP en la zona costera y período de estudio, se elaboró, haciendo uso del programa SURFER, una imagen que representó la variación mensual de la temperatura a lo largo de la costa.

\section{Determinación de focos y zonas de surgencia}

Con el objeto de determinar la localización de las surgencias, se estimó la TSMP mensual y anual de cada subárea, de acuerdo con el siguiente procedimiento:

$$
T S M P_{d k}=\frac{1}{20} \sum_{i=1}^{2} \sum_{j=1}^{10} T S M_{d i j k}
$$

$$
\begin{aligned}
& \text { TSMP }_{\mathrm{dk}}=\text { TSM promedio del día d, en la } \\
& T S M P_{m k}=\frac{1}{n} \sum_{d=1}^{\mathrm{n}} T S M P_{d m k}
\end{aligned}
$$

TSMP $_{\mathrm{dmk}}=$ TSMP del día $\mathbf{d}$, del mes $\mathbf{m}$, en la subárea $\mathbf{k}$.

TSMP $_{\text {mk }}=$ TSMP del mes m, en la subárea $\mathbf{k}$. 


$$
T S M P_{m}=\frac{1}{120} \sum_{k=1}^{120} T S M P_{m k}
$$

TSMP $_{\mathrm{m}}=$ TSMP de la banda costera en el mes m.

$$
T S M P_{a k}=\frac{1}{12} \sum_{m=1}^{12} T S M P_{m k}
$$

$\operatorname{TSMP}_{\text {ak }}=\underset{\text { la subárea } \mathbf{k} .}{\text { TSMP del ão }}$

Para eliminar el efecto latitudinal, la $\mathrm{TSMP}_{\mathrm{ak}} \mathrm{se}$ filtró a través de un ajuste lineal; de esta manera se generó una señal latitudinal destendenciada denominada DeltaTSM. Los focos de surgencia se definieron como aquellos lugares geográficos donde se visualizaron los máximos valores negativos de la curva destendenciada. Como zona de surgencia se consideró al conjunto de lugares que presentaron en forma continua tales valores negativos en dicha curva.

El valor negativo de DeltaTSM se consideró indicador de enfriamiento costero y de surgencia, empleándose como valor absoluto en el análisis estadístico. Lo anterior fue validado con la información obtenida del análisis visual de las imágenes diarias de TSM.

Estimación de la duración e intensidad de los eventos de surgencias

Para analizar la duración de los eventos de surgencia, se efectuó en primer lugar un análisis multitemporal de las imágenes diarias disponibles, con el objeto de visualizar el dinamisno temporal de éstos. Luego se realizó un tratamiento digital, empleando la información de la TSMP integrada de la franja costera, para analizar la variación interdiaria de cada zona de surgencia durante el período estival. Se consideró esta estación del año, dado que las otras estaciones presentaron importantes vacíos a causa de los días nublados.

Con este objeto se generó para cada zona de surgencia una serie de tiempo de la TSMP con un rezago de un día. Los datos faltantes (1 ó 2) se completaron considerando el método de interpolación lineal. Si la falta de datos superó los tres días, la serie se interpoló considerando los datos de TSM registrados en estaciones costeras (de Arica, Iqui- que y Antofagasta), ponderados en base a la distancia de dichas estaciones.

Para determinar la duración de las surgencias, las series diarias de la TSMP de las distintas zonas de surgencia fueron filtradas con un coseno Lanczos de 121 pesos y un filtro Hanning, lo cual pennitió mantener las fluctuaciones de 3 a 20 días (Bravo, 1993). Luego se consideró que los valores negativos de alta frecuencia de dichas curvas penniten identificar enfriamientos que corresponderían a eventos de surgencia. El resultado fue validado efectuando un análisis visual de las imágenes disponibles.

La intensidad de las surgencias se determinó considerando su duración y extensión, además de la variación de la TSM durante el evento, tomando en cuenta la amplitud de la señal diaria por zona.

\section{Información meteorológica}

La información sobre la dirección y magnitud del viento en las estaciones de Chacalluta $\left(18^{\circ} 28^{\prime} \mathrm{S}\right)$ y Diego Aracena (2326'S) fue proporcionada por la Dirección Meteorológica de Chile. Con esta información se calculó el índice diario de surgencia de Bakun (Bakun, 1973). Luego, considerando los valores diarios de la TSMP de las zonas de surgencias y de dicho índice de surgencia, se efectuó un análisis de correlación cruzada.

\section{RESULTADOS}

\section{Cobertura de nubes}

De la clasificación de las imágenes diarias disponibles se desprende que el porcentaje de información libre de nubes es mayor en el sector costero (Fig. 1). También se observa que el grado de cobertura de nubes presenta una marcada estacionalidad, principalmente en la zona costera, siendo mayor en invierno y menor en verano. Cabe señalar que durante el período de estudio, el porcentaje promedio mensual de imágenes de categoría B (buena) es de sólo $9 \%$ en el sector oceánico, de $9 \%$ en el sector intermedio y de más de $33 \%$ en el sector costero. También se observa que estos valores presentan variaciones interanuales; es así como en 1988 se presenta la mayor cobertura de nubes del período y en 1992 la menor (Tabla 1). 


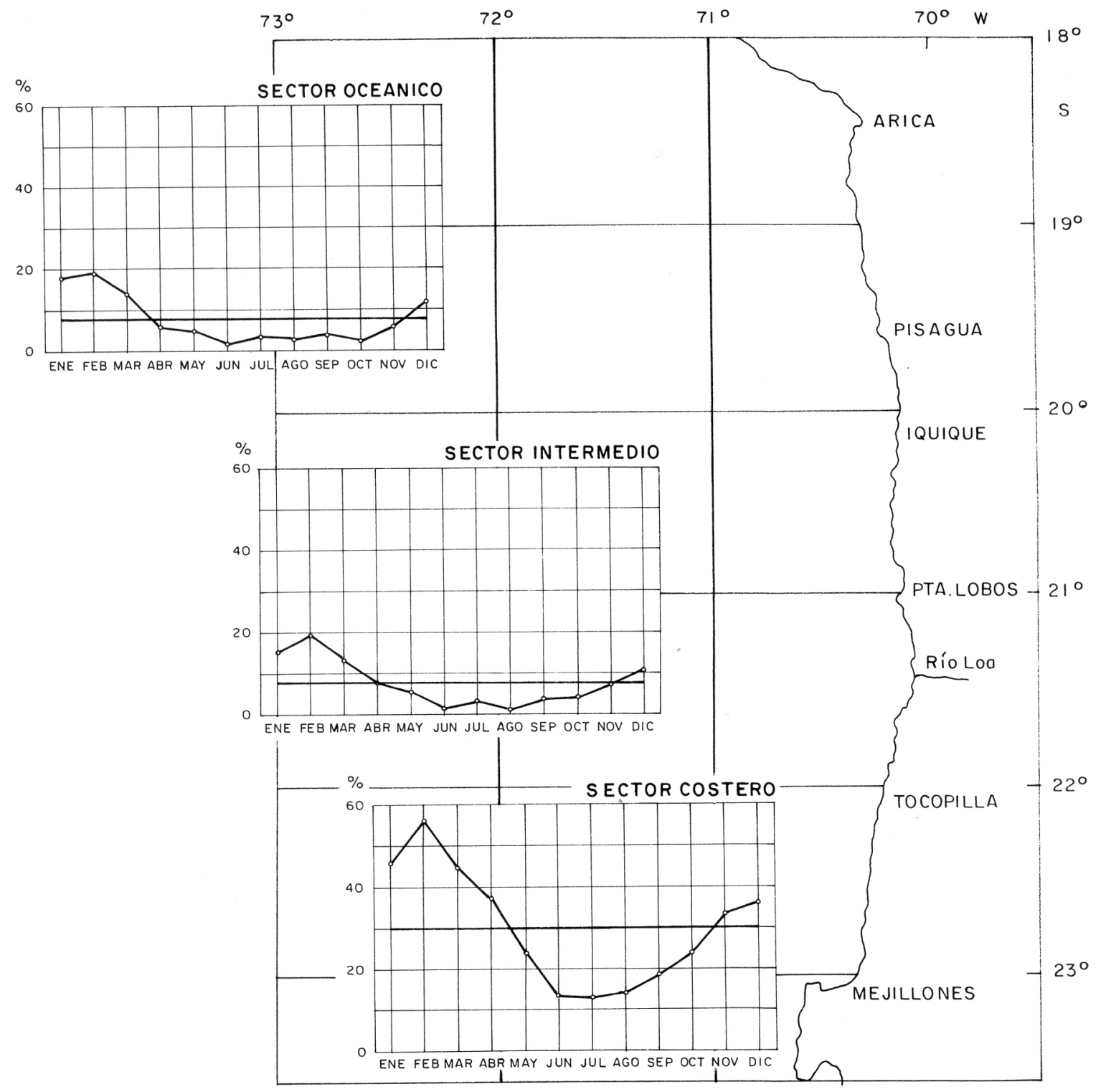

Figura 1. Zona de estudio y porcentajes mensuales promedio (\%) de información libre de cobertura de nubes por sector (costero, intermedio y oceánico) en el período 1987-92.

\section{Temperatura superficial del mar}

En la Fig. 2 se observan los valores de la TSMP de la franja costera, donde se evidencia una clara estacionalidad, con una estación cálida que se inicia en octubre y finaliza en abril. Durante el período de estudio la TSMP $\mathrm{m}$ oscila entre $16^{\circ}$ y $22^{\circ} \mathrm{C}$; los valores máximos se presentan en febrero, con excepción de 1992 en que el máximo se presenta en marzo. Se observa que durante El Niño de 1987 la $\mathrm{TSMP}_{\mathrm{m}}$ presenta valores superiores en $1,5^{\circ} \mathrm{C}$ durante todo el año, mientras que durante El Niño de 1992 esta anomalía se presenta de marzo a mayo y de septiembre a noviembre.

Del análisis visual de las imágenes diarias de categorías B y R, en la Tabla 2 se muestra la TSM máxima y mínina mensual por año, esta última representa la temperatura mínima de aguas surgentes. El rango mayor entre ambas TSM es de 5 a $6^{\circ} \mathrm{C}$, y se produce 
Tabla 1. Porcentajes anuales por sector de imágenes satelitales buenas (B), regulares (R) y malas (M), en términos de cobertura de nubes.

\begin{tabular}{|c|c|c|c|c|c|c|c|c|c|c|c|c|}
\hline \multirow[t]{3}{*}{ AÑO } & \multicolumn{9}{|c|}{ SECTOR } & \multicolumn{3}{|c|}{ TOTAL } \\
\hline & \multicolumn{3}{|c|}{ COSTERO } & \multicolumn{3}{|c|}{ INTERMEDIO } & \multicolumn{3}{|c|}{ OCEANICO } & & & \\
\hline & B & $\mathrm{R}$ & M & B & $\mathrm{R}$ & $\mathbf{M}$ & B & $\mathrm{R}$ & $M$ & B & $\mathrm{R}$ & $M$ \\
\hline 1987 & 27 & 7 & 66 & 7 & 9 & 84 & 7 & 8 & 85 & 14 & 8 & 78 \\
\hline 1988 & 23 & 10 & 67 & 5 & 7 & 88 & 5 & 6 & 89 & 11 & 7 & 81 \\
\hline 1989 & 39 & 16 & 46 & 10 & 8 & 82 & 9 & 7 & 84 & 19 & 10 & 70 \\
\hline 1990 & 34 & 11 & 55 & 7 & 6 & 88 & 6 & 5 & 88 & 16 & 7 & 77 \\
\hline 1991 & 39 & 20 & 42 & 8 & 17 & 75 & 10 & 16 & 74 & 19 & 18 & 63 \\
\hline 1992 & 34 & 18 & 47 & 13 & 9 & 78 & 13 & 8 & 78 & 20 & 12 & 68 \\
\hline TOTAL & 33 & 14 & 54 & 9 & 9 & 82 & 9 & 8 & 83 & 17 & 10 & 73 \\
\hline
\end{tabular}

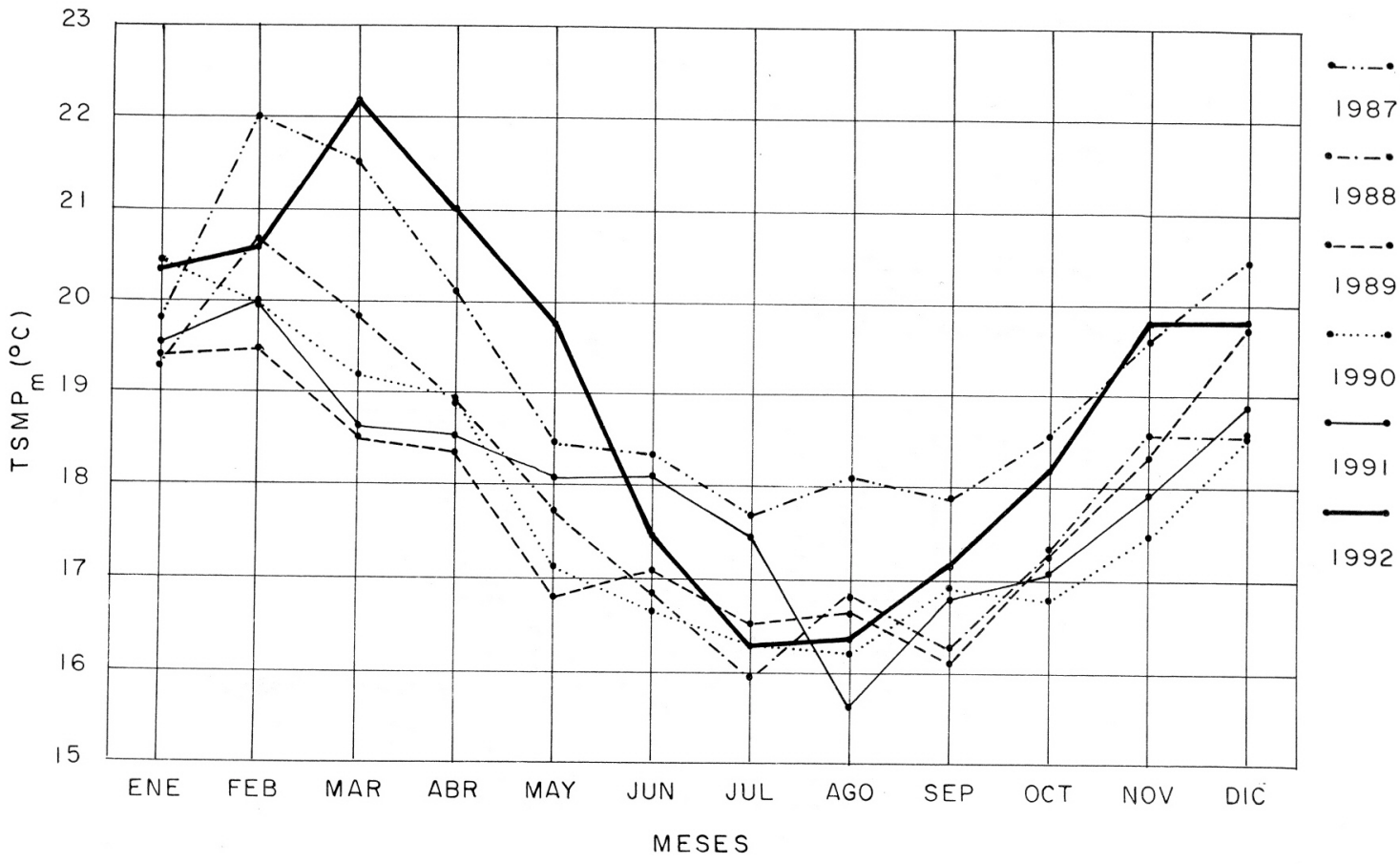

Figura 2. Estacionalidad de la TSMP en la franja costera durante el período 1987-92.

en febrero o marzo. En estos meses la TSM máxima alcanza valores de $24^{\circ} \mathrm{C}$ en años normales y de $25^{\circ} \mathrm{C}$ durante los años El Niño 1987 y 1992. El rango mínimo de la TSM se presenta en invierno, siendo habitualmente de $3^{\circ} \mathrm{C}$; sin embargo, este es de $2^{\circ} \mathrm{C}$ en julio y agosto de 1989, 1990 y 1992. La TSM en invierno es de $15^{\circ} \mathrm{C}$ en años normales, pero disminuye a $14^{\circ} \mathrm{C}$ en inviernos muy fríos (1988).

La isoterma de la TSM surgente observada en las imágenes diarias es de $18-19^{\circ} \mathrm{C}$ en la estación cálida (octubre-abril), y de $15-16^{\circ} \mathrm{C}$ en la estación fóa (mayo-septiembre).

En la Fig. 3 se puede apreciar la notable variabi-

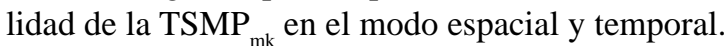
En el modo temporal se observa una clara estacionalidad y marcadas variaciones interanuales. En efecto, los años son notablemente cálidos en 1987 y 1992, en tanto que el verano de 1989 es el más frío del período de estudio. En el modo espacial se obser- 
Tabla 2. Temperaturas superficiales del $\operatorname{mar}\left(\operatorname{TSM}^{\circ}{ }^{\circ} \mathrm{C}\right)$ de la zona norte de Chile registradas con satélites NOAA, durante el período 1987-92.

\begin{tabular}{|c|c|c|c|c|c|c|c|c|c|c|c|c|c|}
\hline RASGO & AÑO & ENE & FEB & MAR & $\mathrm{ABR}$ & MAY & JUN & JUL & AGO & SEP & OCT & NOV & DIC \\
\hline $\begin{array}{c}\text { TSM } \\
\text { MAXIMA }\end{array}$ & $\begin{array}{l}1987 \\
1988 \\
1989 \\
1990 \\
1991 \\
1992\end{array}$ & $\begin{array}{l}25 \\
24 \\
23 \\
24 \\
24 \\
23\end{array}$ & $\begin{array}{r}24-25 \\
24 \\
24 \\
24 \\
24 \\
24-25\end{array}$ & $\begin{array}{r}24-25 \\
23-24 \\
24 \\
23 \\
23 \\
25\end{array}$ & $\begin{array}{r}24 \\
22-23 \\
23 \\
22 \\
21 \\
24-23\end{array}$ & $\begin{array}{r}21 \\
20-21 \\
21 \\
20 \\
21 \\
22\end{array}$ & $\begin{array}{r}19-20 \\
19 \\
19 \\
19 \\
19 \\
20-19\end{array}$ & $\begin{array}{r}19 \\
17 \\
18 \\
17 \\
18-19 \\
18\end{array}$ & $\begin{array}{l}19 \\
18 \\
19 \\
17 \\
17 \\
18\end{array}$ & $\begin{array}{l}20 \\
18 \\
19 \\
18 \\
17 \\
19\end{array}$ & $\begin{array}{l}21 \\
20 \\
20 \\
19 \\
21 \\
20\end{array}$ & $\begin{array}{r}22 \\
21-23 \\
20 \\
20 \\
21 \\
22\end{array}$ & $\begin{array}{r}23-24 \\
22-24 \\
23 \\
22 \\
23 \\
23\end{array}$ \\
\hline $\begin{array}{c}\text { TSM } \\
\text { DOMINANT } \\
\text { E }\end{array}$ & $\begin{array}{l}1987 \\
1988 \\
1989 \\
1990 \\
1991 \\
1992\end{array}$ & $\begin{array}{r}22-23 \\
22-21 \\
22 \\
23 \\
21 \\
22\end{array}$ & $\begin{array}{r}23-24 \\
22 \\
23 \\
23 \\
22 \\
23\end{array}$ & $\begin{array}{r}23 \\
22 \\
23 \\
21 \\
22 \\
23-24\end{array}$ & $\begin{array}{r}22 \\
21 \\
21 \\
21-20 \\
20 \\
21\end{array}$ & $\begin{array}{l}20 \\
20 \\
20 \\
19 \\
19 \\
20\end{array}$ & $\begin{array}{r}19 \\
18-19 \\
18 \\
- \\
19 \\
19-18\end{array}$ & $\begin{array}{r}17 \\
17 \\
18 \\
- \\
18 \\
17\end{array}$ & $\begin{array}{r}17 \\
17 \\
18 \\
18 \\
16-17 \\
17\end{array}$ & $\begin{array}{r}17-18 \\
16 \\
18 \\
18 \\
17 \\
17\end{array}$ & $\begin{array}{l}19 \\
19 \\
19 \\
18 \\
18 \\
18\end{array}$ & $\begin{array}{l}20 \\
19 \\
19 \\
19 \\
19 \\
21\end{array}$ & $\begin{array}{r}22 \\
20 \\
21-22 \\
20 \\
21 \\
21\end{array}$ \\
\hline $\begin{array}{c}\text { TSM } \\
\text { MINIMA }\end{array}$ & $\begin{array}{l}1987 \\
1988 \\
1989 \\
1990 \\
1991 \\
1992\end{array}$ & $\begin{array}{r}18-20 \\
18 \\
18 \\
17 \\
18 \\
18\end{array}$ & $\begin{array}{l}19 \\
18 \\
17 \\
17 \\
18 \\
19\end{array}$ & $\begin{array}{r}19-20 \\
17-18 \\
17 \\
16 \\
17 \\
19\end{array}$ & $\begin{array}{r}16-17 \\
16 \\
16 \\
16 \\
17 \\
18\end{array}$ & $\begin{array}{r}16 \\
15-17 \\
15 \\
15 \\
16 \\
16\end{array}$ & $\begin{array}{r}16 \\
14-15 \\
15-16 \\
15 \\
16 \\
15-16\end{array}$ & $\begin{array}{r}16 \\
14-15 \\
15-16 \\
15 \\
16 \\
15\end{array}$ & $\begin{array}{l}15 \\
14 \\
16 \\
15 \\
14 \\
15\end{array}$ & $\begin{array}{r}16 \\
14 \\
16 \\
15 \\
14-15 \\
16\end{array}$ & $\begin{array}{r}16 \\
16 \\
16-17 \\
15 \\
15 \\
16\end{array}$ & $\begin{array}{r}18 \\
16-17 \\
18 \\
16 \\
15-16 \\
18\end{array}$ & $\begin{array}{r}18 \\
17-18 \\
18 \\
17 \\
16-17 \\
18\end{array}$ \\
\hline
\end{tabular}

bien definido; en efecto, la franja costera no presenta una TSM uniforme, sino lugares que se caracterizan por presentar normalmente aguas más cálidas y otros más frías. La interpretación de esta observación permite señalar que en la zona de estudio existe un proceso de enfriamiento costero, que se presenta como eventos de surgencia por focos (Fig. 4a) y como franjas frías (Fig. 4b), a lo largo de la costa (Tabla 3).

\section{Surgencias costeras}

\section{Ubicación geográfica}

La señal de la TSMP ${ }_{\mathrm{ak}}$ muestra una clara tendencia latitudinal con altos valores desde los $18^{\circ} \mathrm{S}$ hasta Iquique $\left(20^{\circ} 10^{\prime} \mathrm{S}\right)$, los cuales tienden a disminuir hacia el sur (Fig. 5). Estas curvas muestran que durante los años El Niño de 1987 y 1992 se presentan las TSMP más altas, en tanto que en 1989 y 1990 se observan las más bajas. Al comparar las curvas, utilizando el test de KolmogorovSmirnov, se concluye que entre los años 1987 y 1992 se presentan diferencias estadísticas significativas, en tanto que entre los años 1989 y 1990, y 1988 y 1991 no se presentan dichas diferencias.

En la Fig. 6 se presenta la variación anual del DeltaTSM a lo largo de la franja costera, donde los picos negativos máximos representan focos de surgencia; éstos y los picos negativos contiguos forman zonas de surgencia. De esta manera se ubicaron geográficamente 8 focos de surgencia asociados a 5 zonas (Tabla 4). Se destaca la zona de surgencia ubicada al sur de Iquique, que representa 4 focos y que abarca una importante extensión latitudinal. Por otro lado, la de punta Arenas en algunos años presenta picos negativos débiles y la existencia de la surgencia es validada en la observación directa de las imágenes satelitales.

Las señales anuales del DeltaTSM indican que en las zonas de Pisagua, Mejillones y sur de Iquique las surgencias presentan grados análogos de importancia durante los 6 años del estudio. En algunos casos cambia el grado de importancia de algunos focos; en la zona de Mejillones, por ejemplo, se presenta normalmente el mayor gradiente térmico (Fig. 6). El foco del sur de Arica se presenta durante los 6 años, pero disminuye su importancia en 1988. En la zona del sur del río Loa es observado un enfriamiento en las imágenes satelitales, pero, en la señal del DeltaTSM éste no es claramente detectado, particularmente en 1988, 1989 y 1992. Se deduce entonces que las zonas de surgencia se mantienen durante el período de estudio, no obstante que cambia la importancia relativa de los focos.

Al comparar con análisis de varianza (ANDEVA) los valores anuales absolutos de los DeltaTSM de 4 zonas de surgencia, es decir, sin considerar la del sur del río Loa debido al dudoso valor del índice, se constatan diferencias significativas $(\mathrm{Fcal}=65,54$; Ftabla 


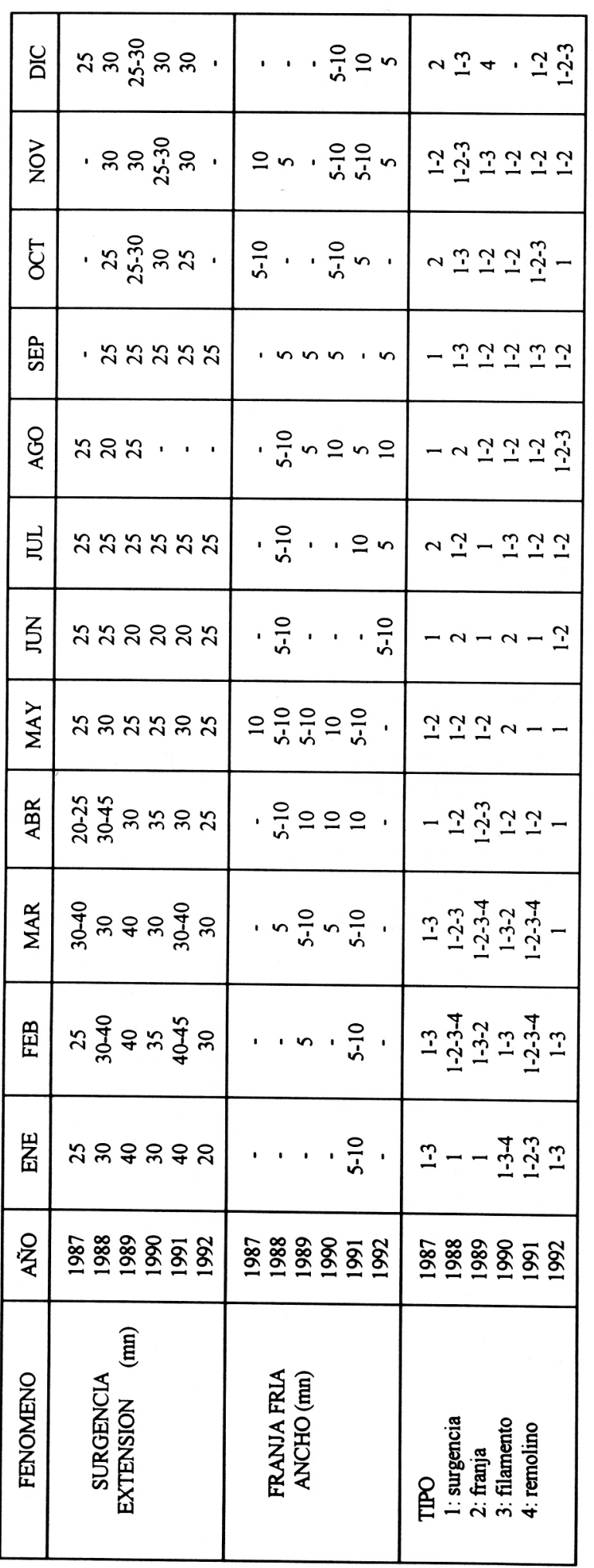


Tabla 4. Ubicación geográfica de zonas y focos de surgencia.

\begin{tabular}{|l|l|c|}
\hline \multicolumn{1}{|c|}{ ZONA } & \multicolumn{1}{|c|}{ FOCO } & UBICACION \\
\hline 1) Sur de Arica & Punta Baquedano & $18^{\circ} 35^{\prime} \mathrm{S}-70^{\circ} 20^{\prime} \mathrm{W}$ \\
2) Pisagua & Punta Pichalo & $19^{\circ} 35^{\prime} \mathrm{S}-70^{\circ} 15^{\prime} \mathrm{W}$ \\
& & \\
3) Sur de Iquique & Punta Chucumata & $20^{\circ} 31^{\prime} \mathrm{S}-70^{\circ} 12^{\prime} \mathrm{W}$ \\
& Punta Yapes & $20^{\circ} 40^{\prime} \mathrm{S}-70^{\circ} 11^{\prime} \mathrm{W}$ \\
& Punta Patache & $20^{\circ} 48^{\prime} \mathrm{S}-70^{\circ} 2^{\prime} \mathrm{W}$ \\
& Punta Lobos & $21^{\circ} 01^{\prime} \mathrm{S}-70^{\circ} 10^{\prime} \mathrm{W}$ \\
& & $21^{\circ} 38^{\prime} \mathrm{S}-70^{\circ} 09^{\prime} \mathrm{W}$ \\
& & \\
4) Sur del Río Loa & Punta Arenas & $23^{\circ} 02^{\prime} \mathrm{S}-70^{\circ} 31^{\prime} \mathrm{W}$ \\
& & \\
\hline \multirow{2}{*}{ 5) Mejillones } & Punta Angamos & \\
& &
\end{tabular}

$=2,84 ; \mathrm{p}<0,05)$. En efecto, la aplicación del test DMS entre dos zonas pennite confinnar dichas diferencias en $n-1=5$ casos $(p<0,05)$, salvo entre la zona del sur de Arica y la de Pisagua ( $>>0,05)$.

\section{Extensión espacial}

La lengua surgente, medida desde la costa hacia la zona oceánica, presenta durante el período de estudio una extensión de entre 20 y $45 \mathrm{mn}$ (Tabla 3a). Esta extensión cambia intennensualmente, siendo generalmente de 30 a 40 mn durante los meses cálidos de principios de año (enero a abril), y de 20 a $25 \mathrm{mn}$ en invierno e inicios de primavera (junio a septiembre). La extensión de la surgencia presenta también variaciones interanuales, durante 1989, por ejemplo, ésta fue mayor. Al comparar la extensión de las lenguas surgentes de verano, se observa que durante los fenómenos El Niño de 1987 y 1992 éstas generalmente alcanzaron sólo las 20-30 mn. Por otra parte, durante la primavera de 1987 dichas lenguas sólo alcanzaron las $20 \mathrm{mn}$, mientras que en las primaveras de los otros años éstas alcanzan las 25-30 mn.

En las distintas zonas, la pluma surgente es normalmente de dirección $\mathrm{W}$ y NW, con excepción de la zona de Mejillones donde la dirección es generalmente hacia el norte. El gradiente ténnico del borde de la pluma surgente varía entre 0,1 y $0,6^{\circ} \mathrm{C} /$ $\mathrm{mn}$, siendo mayor en verano y menor en invierno. Al comparar las imágenes de los meses de verano de los 6 años de estudio, se concluye que en 1989 se presentaron los gradientes más altos.

En las imágenes de TSM se observan franjas frías costeras (Fig. 4b), que desde la costa miden entre 5 y $10 \mathrm{mn}$ (Tabla 3b). Estas se presentan principalmente entre marzo y mayo, y entre agosto y noviembre, disminuyendo durante los años El Niño de 1987 y 1992. Estas franjas frías se presentan también durante los meses cálidos, cuando se producen eventos de surgencia consecutivos en el tiempo y en focos contiguos.

\section{Duración y ocurrencia}

En la Tabla 5 se presentan los resultados del análisis de las cinco zonas de surgencia durante los meses de enero a abril (los menos afectados por la nubosidad), del período 1987-92. Se puede apreciar que durante estos meses el número de eventos de surgencia en las distintas zonas varía de un año a otro. Cabe recordar que dichos eventos se presentan durante todo el año, alternándose con períodos de relajamiento.

Durante los meses antes mencionados, el número de eventos de surgencia es nonualmente mayor en el norte de la zona de estudio. En 1990, por ejemplo, se observaron 11 eventos en punta Baquedano y 11 en la zona de Pisagua, 9 al sur de Iquique, 8 al sur del río Loa y 9 en punta Angamos (Tabla 5). Esta tendencia se mantiene prácticamente durante todo el período de estudio, alterándose sólo en 1987 y 1992 donde se presenta un mayor número de eventos en la zona sur de Iquique y en la de Mejillones (Tabla 5).

La duración de los eventos de surgencia, determinada a través del análisis visual de las imágenes, es variable y oscila entre 4 y 15 días. Los eventos de mayor duración se presentan a fines del verano e inicios de otoño, mientras que los de menor duración se observan durante los meses de invierno y primavera. La alta nubosidad que se presenta en esta época del año, limita el análisis diacrónico de las imágenes, lo que dificulta la detenninación de la duración de los eventos.

Considerando los resultados antes señalados, se realiza un tratamiento digital de las imágenes de los 4 primeros meses del período 1988-92 (aunque sólo se entregan los resultados de 1989 y 1992). Para tal efecto, se considera como evento de surgencia a los enfriamientos costeros de una duración superior a 3 días y cuya amplitud del DeltaTSM sea superior a $0,31^{\circ} \mathrm{C}$. Es así como se detennina que durante los veranos fríos de 1989 y 1991, dicha amplitud alcanza los $-2,5^{\circ} \mathrm{C}$, en tanto que en el verano de 1990 ésta alcanza a $-1,4^{\circ} \mathrm{C}$ (Fig. 3). 


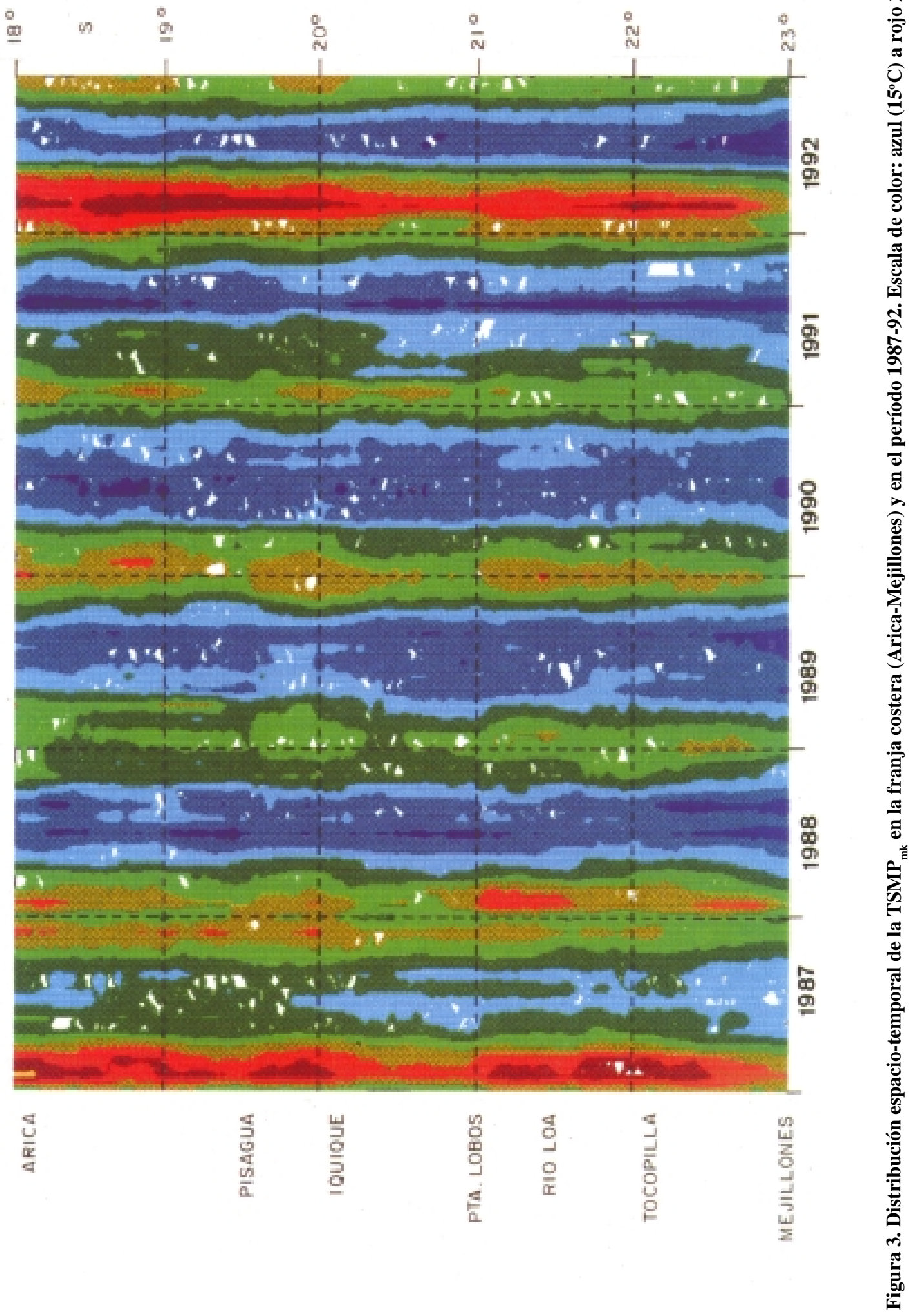


a)

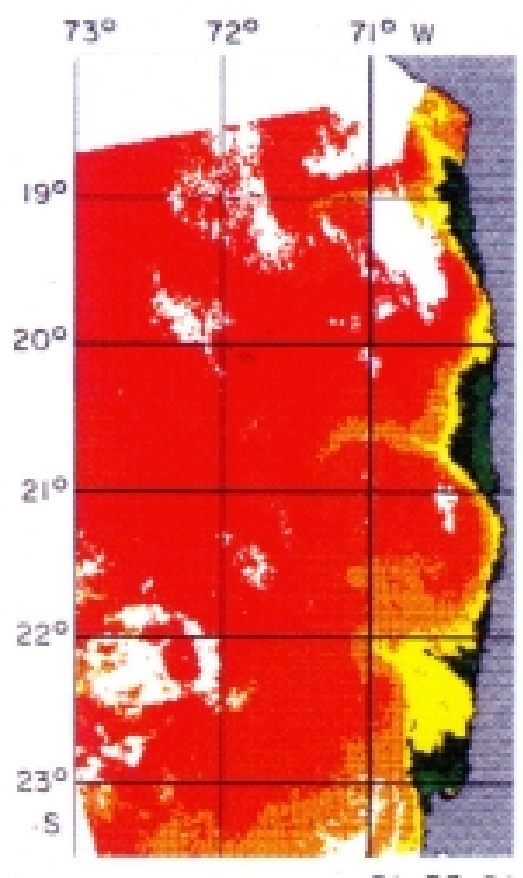

b)

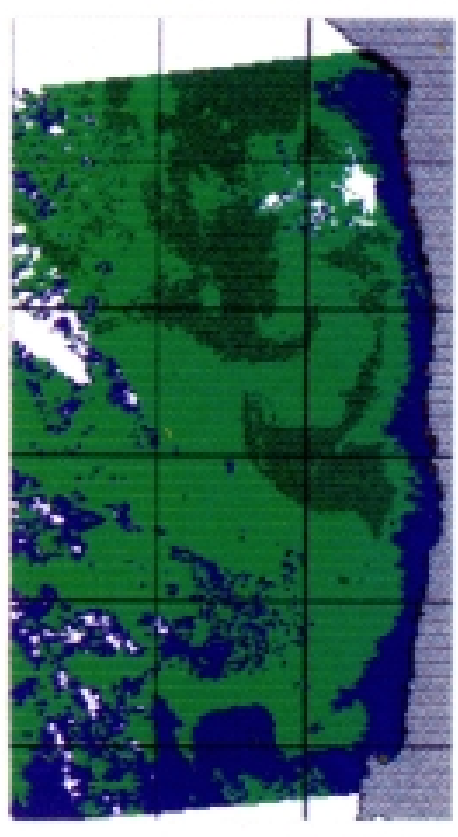

13.09 .89
$\operatorname{Tsh}\left({ }^{\circ} \mathrm{C}\right)$

$24^{\circ}$

$22^{\circ}$

22

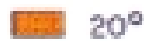

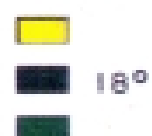

$16^{\circ}$

$14^{\circ}$

E. 120

Costo

Figura 4. Imágenes satelitales de TSM: a) focos surgentes y b) franja fría.

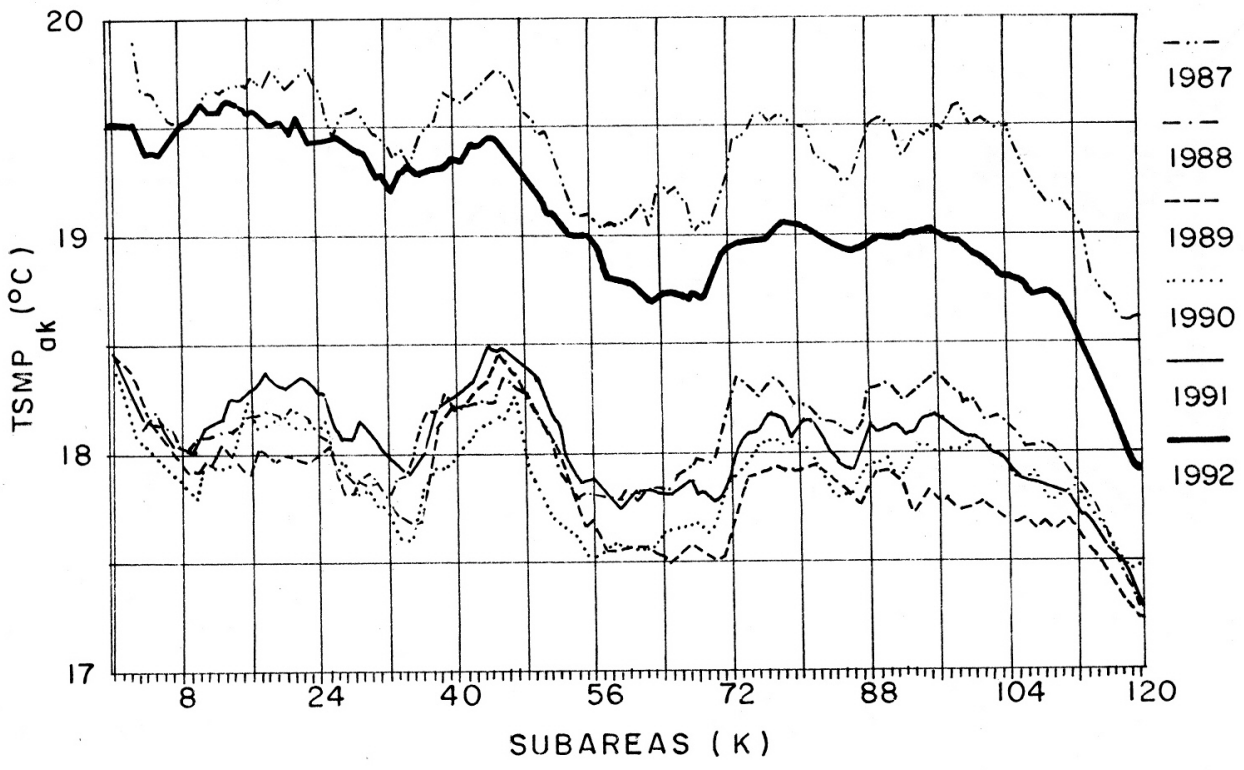

Figura 5. Señales de la TSMP ${ }_{\mathrm{ak}}$ a lo largo de la franja costera durante el período 1987-92. 


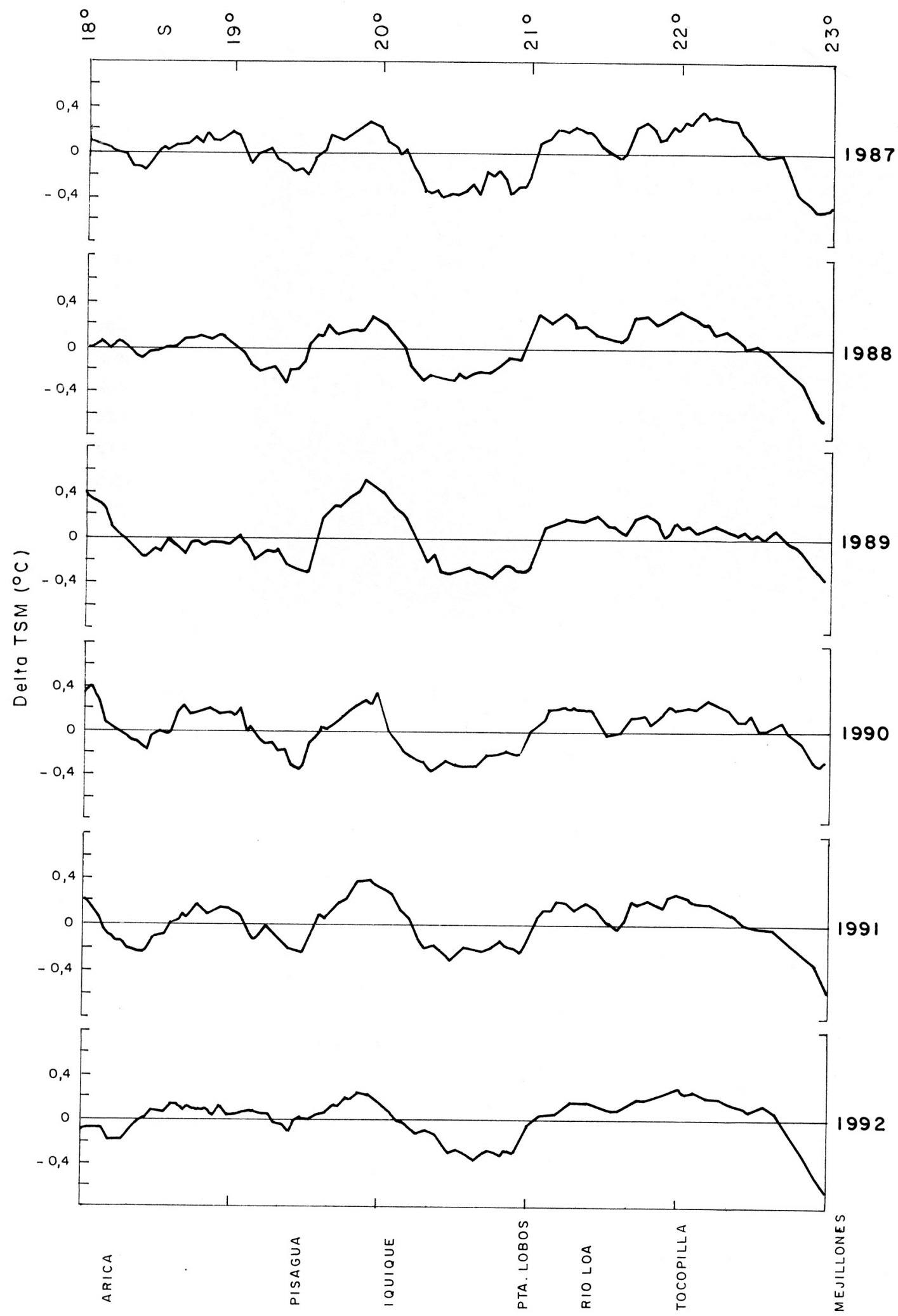

Figura 6. Señales anuales del DeltaTSM a lo largo de la franja costera . 

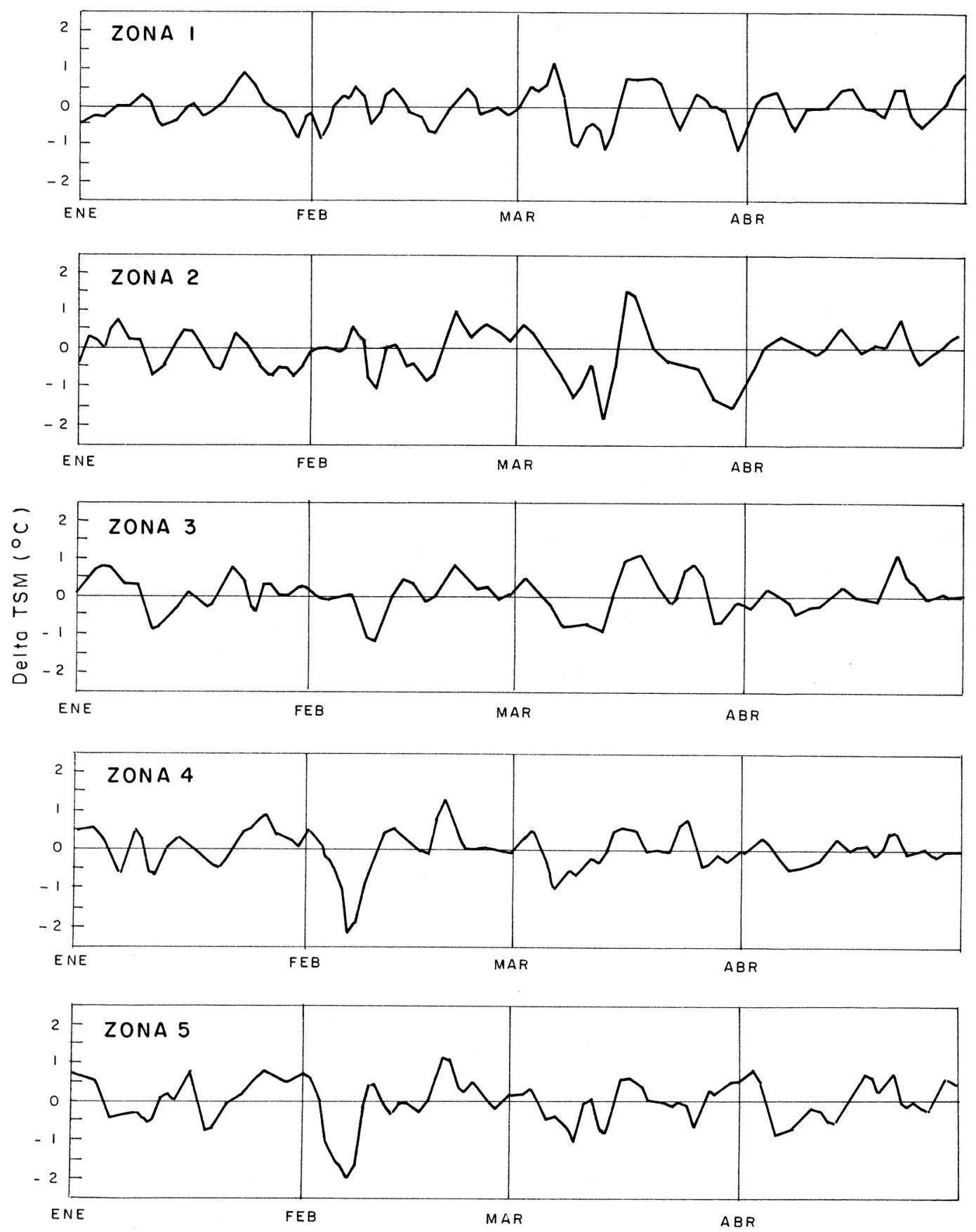

Figura 7. Señales diarias del DeltaTSM de enero a abril de 1989 en distintas zonas de surgencia. 
En 1989, por ejemplo, la señal diaria del DeltaTSM indica que los eventos de surgencia no se producen en forma simultánea en las cinco zonas (Fig. 7). No obstante, se observa un cierto sincronismo en el momento en que se producen los eventos de surgencia en la zona de estudio. Esto ocurre ocasionalmente durante los meses de febrero y marzo, cuando se presentan eventos intensos. En estas ocasiones los eventos se desarrollan con un desfase de 2 días entre zonas. De este modo, los eventos se producen primero en la zona de Mejillones (zona 5) y luego sucesivamente hacia el norte.

En 1992, los eventos de surgencia de la zona sur de Anca (zona 1) y de Pisagua (zona 2) presentan sincronismo, mientras que entre la zona del sur de Iquique (zona 3) y la de Mejillones (zona 5) el comportamiento es análogo (Fig. 8). Cabe señalar que en punta Arenas (zona 4) los eventos de surgencia pierden intensidad, razón por la cual no se consideran en este análisis específico.

\section{Intensidad}

La intensidad de la surgencia, vista en superficie con la técnica satelital, presenta variabilidad. El análisis de correlación múltiple entre la variación del DeltaTSM, la duración y extensión de los eventos de surgencia, permite señalar asociación, aunque débil, entre el DeltaTSM y la extensión $(r=0,3158)$, Y entre el DeltaTSM y la duración $(r=0,4023)$; $\sin$ embargo, entre la extensión y la duración no existe asociación (Tabla 6).

Al analizar la información en forma más segmentada, se observa que en punta Baquedano la asociación entre la duración, el DeltaTSM y la intensidad de las surgencias es significativa $(r=0,5926$ y 0,6788 respectivamente), mientras que no lo es entre la duración y la extensión $(\mathrm{r}=0,1124)$ (Tabla 7a). En las zonas de Pisagua y del sur de Iquique los coeficientes de correlación parcial entre la duración y la extensión de los eventos es de -0,4612 y - $-0,656$ respectivamente, ambos significativos (Tabla 7a). Cabe señalar que en estas zonas se presentan eventos de hasta 15 días (Tabla 5), pero esto reflejaría eventos que se producirían uno a continuación del otro, lo cual no se refleja en una mayor extensión de la lengua surgente.

Para el período 1989-91, los coeficientes de correlación parcial entre la intensidad y la duración son significativos en las zonas de surgencia 1 y 2 (sur de Arica y Pisagua), lo mismo que en la zona 3 (sur de
Iquique) en 1989 y 1990 (Tabla 7.b). Esto no sucede en 1991 en la zona 3, donde se presenta un número reducido de eventos aunque de un fuerte gradiente.

Finalmente, se estableció una asociación significativa, con un desfase de un día, entre el DeltaTSM de la zona de surgencia ubicada al sur de Iquique y el índice de surgencia de Bakun calculado con los vientos de la estación meteorológica de Iquique (Fig. 9). Los análisis de correlación cruzada, entre el DeltaTSM diario de las otras zonas de surgencia y el índice de Bakun estimado diariamente con los vientos de las estaciones meteorológicas más cercanas, no arrojaron asociaciones significativas.

\section{Filamentos y remolinos}

El análisis visual de la imágenes disponibles del período 1987-92, permite apreciar la presencia de filamentos que se desarrollan desde el borde de la pluma surgente; éstos pueden ser largos y delgados, o medianos, cortos y anchos, y presentan una longitud promedio de $60 \mathrm{mn}$, alcanzando las $100 \mathrm{mn}$ (Fig. 10). Los filamentos se presentan prácticamente durante todos los meses, no obstante que serían más numerosos entre noviembre y abril (Tabla 8). Debe señalarse que en el período 1988-90 durante los meses de junio y agosto no se registran filamentos, debido probablemente al bajo número de imágenes disponibles y a la alta presencia de nubes en esa época del año en el área de estudio.

En la Tabla 8 se presenta una breve descripción de los filamentos según su longitud y ubicación. En la zona de Mejillones se registra la mayor presencia de filamentos, en casi todos los meses, éstos son cortos y medianos, y la componente $\mathrm{N}$ es importante en su distribución. Le sigue en importancia, en cuanto al número de filamentos observados, la zona del sur de Iquique; en esta zona los filamentos son preferentemente largos y de dirección $\mathrm{W}$ y NW, aunque también se presentan con giros al SW. Entre punta Arenas y Tocopilla los filamentos son preferentemente de longitud media y de dirección NW. En la zona de Anca y Pisagua no se registran filamentos en invierno e inicio de primavera; en todo caso, los filamentos observados presentan una fuerte componente $\mathrm{W}$ y después de varios días de permanencia, se orientan hacia el sur.

Debido a la baja frecuencia de imágenes en ciertas épocas del año, no es fácil hacer el seguimiento 
Tabla 5. Eventos de surgencia observados en las imágenes satelitales por zona, entre enero y abril, durante el período 1987-92: a) ocurrencia (número de días), b) duración máxima (días), y c) duración promedio (días).

\begin{tabular}{|c|c|c|c|c|c|c|c|c|c|c|c|c|c|c|c|c|c|c|c|}
\hline \multirow{2}{*}{ ZONA } & \multirow{2}{*}{ MES } & \multicolumn{3}{|c|}{1987} & \multicolumn{3}{|c|}{1988} & \multicolumn{3}{|c|}{1989} & \multicolumn{3}{|c|}{1990} & \multicolumn{3}{|c|}{1991} & \multicolumn{3}{|c|}{1992} \\
\hline & & a & b & c & a & b & c & a & b & c & a & b & c & a & b & c & a & b & c \\
\hline \multirow[t]{2}{*}{1} & $\begin{array}{l}\text { ENE } \\
\text { FEB } \\
\text { MAR } \\
\text { ABR } \\
\end{array}$ & $\begin{array}{l}1 \\
1 \\
2 \\
- \\
\end{array}$ & $\begin{array}{l}5 \\
7 \\
- \\
\end{array}$ & $\begin{array}{r}5 \\
6,5\end{array}$ & $\begin{array}{l}2 \\
1 \\
1 \\
1 \\
\end{array}$ & $\begin{array}{l}7 \\
3 \\
5 \\
4 \\
\end{array}$ & $\begin{array}{l}6 \\
3 \\
5 \\
4 \\
\end{array}$ & $\begin{array}{l}1 \\
4 \\
3 \\
1 \\
\end{array}$ & $\begin{array}{r}10 \\
9 \\
8 \\
4 \\
\end{array}$ & $\begin{array}{r}5,2 \\
5\end{array}$ & $\begin{array}{l}2 \\
4 \\
4 \\
1 \\
\end{array}$ & $\begin{array}{l}7 \\
5 \\
6 \\
6 \\
\end{array}$ & $\begin{array}{r}6 \\
4,5 \\
5,2 \\
- \\
\end{array}$ & $\begin{array}{l}3 \\
2 \\
2 \\
1 \\
\end{array}$ & $\begin{array}{l}5 \\
9 \\
9 \\
6 \\
\end{array}$ & $\begin{array}{r}3,6 \\
6 \\
6,1\end{array}$ & $\begin{array}{l}2 \\
3 \\
2 \\
1 \\
\end{array}$ & $\begin{array}{l}6 \\
6 \\
6 \\
7 \\
\end{array}$ & $\begin{array}{l}5,5 \\
5,5 \\
5,5\end{array}$ \\
\hline & TOTAL & 4 & & & 5 & & & 9 & & & 11 & & & 8 & & & 8 & & \\
\hline \multirow[t]{2}{*}{2} & $\begin{array}{l}\text { ENE } \\
\text { FEB } \\
\text { MAR } \\
\text { ABR } \\
\end{array}$ & $\begin{array}{l}2 \\
2 \\
2 \\
1 \\
\end{array}$ & $\begin{array}{l}5 \\
7 \\
8 \\
4 \\
\end{array}$ & $\begin{array}{r}4,5 \\
6 \\
6 \\
4 \\
\end{array}$ & $\begin{array}{l}2 \\
3 \\
2 \\
- \\
\end{array}$ & $\begin{array}{l}6 \\
6 \\
5 \\
- \\
\end{array}$ & $\begin{array}{r}6 \\
5 \\
4,5 \\
\end{array}$ & $\begin{array}{l}2 \\
2 \\
2 \\
-\end{array}$ & $\begin{array}{r}9 \\
6 \\
15\end{array}$ & $\begin{array}{r}5,3 \\
4,5 \\
11\end{array}$ & $\begin{array}{l}2 \\
4 \\
3 \\
2 \\
\end{array}$ & $\begin{array}{l}9 \\
4 \\
6 \\
3 \\
\end{array}$ & $\begin{array}{r}6 \\
3,2 \\
4,6 \\
3 \\
\end{array}$ & $\begin{array}{l}1 \\
2 \\
2 \\
2 \\
\end{array}$ & $\begin{array}{r}11 \\
6 \\
8 \\
4 \\
\end{array}$ & $\begin{array}{r}- \\
5 \\
6 \\
3,5 \\
\end{array}$ & $\begin{array}{l}2 \\
2 \\
1 \\
2 \\
\end{array}$ & $\begin{array}{l}6 \\
4 \\
7 \\
7 \\
\end{array}$ & $\begin{array}{r}6 \\
3,5 \\
5,5 \\
\end{array}$ \\
\hline & TOTAL & 7 & & & 7 & & & 6 & & & 11 & & & 7 & & & 7 & & \\
\hline \multirow[t]{2}{*}{3} & $\begin{array}{l}\text { ENE } \\
\text { FEB } \\
\text { MAR } \\
\text { ABR } \\
\end{array}$ & $\begin{array}{l}2 \\
2 \\
2 \\
2 \\
\end{array}$ & $\begin{array}{l}5 \\
6 \\
9 \\
5 \\
\end{array}$ & $\begin{array}{l}5 \\
6 \\
7 \\
5 \\
\end{array}$ & $\begin{array}{l}2 \\
3 \\
2 \\
2 \\
\end{array}$ & $\begin{array}{l}6 \\
6 \\
6 \\
5 \\
\end{array}$ & $\begin{array}{r}6 \\
5,5 \\
5 \\
5 \\
\end{array}$ & $\begin{array}{l}2 \\
1 \\
2 \\
1 \\
\end{array}$ & $\begin{array}{r}5 \\
5 \\
10 \\
6 \\
\end{array}$ & $\begin{array}{r}3,6 \\
- \\
8 \\
4 \\
\end{array}$ & $\begin{array}{l}1 \\
4 \\
3 \\
1 \\
\end{array}$ & $\begin{array}{r}14 \\
4 \\
6 \\
6 \\
\end{array}$ & $\begin{array}{l}3,7 \\
5,3\end{array}$ & $\begin{array}{l}3 \\
1 \\
2 \\
1 \\
\end{array}$ & $\begin{array}{l}6 \\
8 \\
7 \\
4 \\
\end{array}$ & $\begin{array}{l}4,6 \\
5,1\end{array}$ & $\begin{array}{l}2 \\
3 \\
3 \\
2 \\
\end{array}$ & $\begin{array}{l}6 \\
9 \\
6 \\
4 \\
\end{array}$ & $\begin{array}{r}5,5 \\
6,6 \\
4 \\
3,5 \\
\end{array}$ \\
\hline & TOTAL & 8 & & & 9 & & & 6 & & & 9 & & & 7 & & & 10 & & \\
\hline \multirow[t]{2}{*}{4} & $\begin{array}{l}\text { ENE } \\
\text { FEB } \\
\text { MAR } \\
\text { ABR }\end{array}$ & $\begin{array}{l}2 \\
1 \\
1 \\
1\end{array}$ & $\begin{array}{l}4 \\
6 \\
4 \\
4\end{array}$ & $\begin{array}{l}4 \\
4 \\
4 \\
4\end{array}$ & $\begin{array}{l}1 \\
3 \\
2 \\
1\end{array}$ & $\begin{array}{l}5 \\
6 \\
6 \\
4\end{array}$ & $\begin{array}{r}5 \\
4,5 \\
5 \\
4\end{array}$ & $\begin{array}{r}11 \\
2 \\
1 \\
-\end{array}$ & $\begin{array}{l}6 \\
8 \\
9 \\
7\end{array}$ & $\begin{array}{r}- \\
7,5\end{array}$ & $\begin{array}{l}2 \\
3 \\
2 \\
1\end{array}$ & $\begin{array}{r}10 \\
8 \\
5 \\
4\end{array}$ & $\begin{array}{r}8 \\
5,3 \\
4,5 \\
-\end{array}$ & $\begin{array}{l}2 \\
3 \\
1 \\
-\end{array}$ & $\begin{array}{l}- \\
-\end{array}$ & $\begin{array}{l}- \\
-\end{array}$ & $\begin{array}{l}2 \\
2 \\
2 \\
2\end{array}$ & $\begin{array}{l}6 \\
4 \\
8 \\
6\end{array}$ & $\begin{array}{r}4,5 \\
4 \\
5 \\
3\end{array}$ \\
\hline & TOTAL & 5 & & & 7 & & & 5 & & & 8 & & & 6 & & & 8 & & \\
\hline \multirow[t]{2}{*}{5} & $\begin{array}{l}\text { ENE } \\
\text { FEB } \\
\text { MAR } \\
\text { ABR } \\
\end{array}$ & $\begin{array}{l}3 \\
3 \\
2 \\
2 \\
\end{array}$ & $\begin{array}{l}6 \\
6 \\
7 \\
5 \\
\end{array}$ & $\begin{array}{r}5 \\
4,5 \\
6,5 \\
5 \\
\end{array}$ & $\begin{array}{l}2 \\
1 \\
2 \\
2 \\
\end{array}$ & $\begin{array}{l}- \\
4 \\
6 \\
5 \\
\end{array}$ & $\begin{array}{r}4 \\
5,5 \\
4,5 \\
\end{array}$ & $\begin{array}{l}1 \\
2 \\
3 \\
1 \\
\end{array}$ & $\begin{array}{r}7 \\
6 \\
6 \\
11 \\
\end{array}$ & $\begin{array}{r}5,5 \\
6 \\
4\end{array}$ & $\begin{array}{l}2 \\
3 \\
3 \\
1 \\
\end{array}$ & $\begin{array}{r}7 \\
7 \\
5 \\
11 \\
\end{array}$ & $\begin{array}{r}5 \\
4,6 \\
4,6\end{array}$ & $\begin{array}{l}2 \\
1 \\
3 \\
1 \\
\end{array}$ & $\begin{array}{l}- \\
- \\
\end{array}$ & $\begin{array}{l}- \\
- \\
\end{array}$ & $\begin{array}{l}2 \\
3 \\
2 \\
2 \\
\end{array}$ & $\begin{array}{l}- \\
: \\
\end{array}$ & - \\
\hline & TOTAL & 10 & & & 7 & & & 7 & & & 9 & & & 7 & & & 9 & & \\
\hline
\end{tabular}

de la evolución de un filamento; no obstante, durante febrero de 1989 se observó un filamento que duró6 días. Cuando los filamentos son largos y se mantienen por varios días, extendiéndose hacia el sur frente a Pis agua y hacia el norte frente a punta Gruesa, se forman remolinos en la zona intermedia, especialmente en febrero (Fig. 10). Una situación análoga se produce al norte de Tocopilla, pero la formación de remolinos es menos evidente. En general los remolinos son poco frecuentes, se observan preferentemente en los meses de diciembre, enero y febrero, y ocasionalmente en marzo.

\section{DISCUSION}

La TSM registrada con satélites contribuye al conocimiento del océano en una perspectiva amplia, pero puede presentar diferencias con valores de la medición clásica realizada con barcos oceanográficos o de oportunidad. Esto puede deberse a que las mediciones desde los barcos es a decímetros o metros bajo la superficie, mientras la TSM adquirida a través de satélites representa la energía infrarroja emi- tida por los primeros milímetros de la superficie del agua (Robinson, 1985). No obstante, esta última permite una descripción de la estructura térmica superficial del mar (Yáñez et al., 1994). De acuerdo con información disponible, se relacionaron TSM registradas en 1988 por barcos cerqueros que operaron en la zona de estudio con instrumentos debidamente calibrados y las obtenidas con satélites NOAA, encontrándose una buena asociación $(\mathrm{r}=0,89)$ (Fig. 11). Asociaciones similare.s han sido encontradas entre las TSM registradas en estaciones de mareógrafo y los de dichos satélites en la zona de estudio (Yáñez et al., 1995).

Las imágenes satelitales del área de estudio registran una importante cobertura nubosa: en el sector oceánico ésta supera el $90 \%$ de los días de invierno y el $70 \%$ de los de verano. Esto dificulta el estudio multitemporal de alta frecuencia de la TSM satelital (como el diario). En el área costera (60 mn de la costa), el porcentaje de imágenes diarias con cobertura nubosa disminuye al $30-40 \%$ en verano (enero, febrero, marzo), lo que permite analizar eventos locales a través de seguimientos diarios. En esta área este tipo de estudios se dificulta en invierno. 

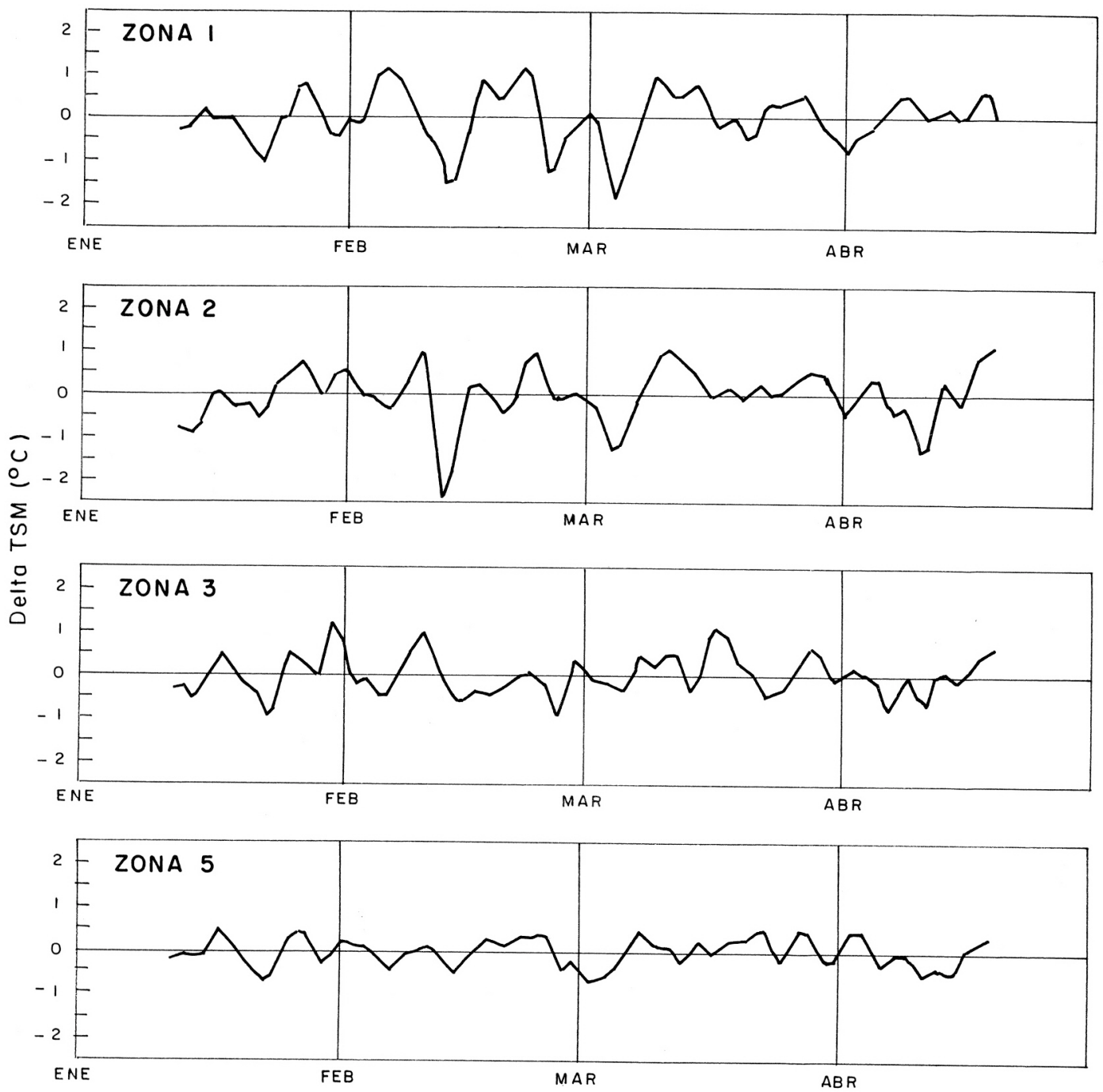

Figura 8. Señales diarias del DeltaTSM de enero a abril de 1992 en distintas zonas de surgencias.

Según Rutllant (1986), la alta nubosidad de la zona norte es debida la inversión térmica de subsidencia de poca altura, que presenta una nubosidad estratocumuliforme que se extiende por debajo de su parte inferior, la que frecuentemente intercepta el relieve costero. Según Fuenzalida (1971), también influye el hecho que la cordillera de la costa esté poco definida y se eleve abruptamente sobre los $1000 \mathrm{~m}$.

Cuando se trata de nubes, éstas son fáciles de identificar por sus bajas temperaturas y quedan registradas en las imágenes e impiden por lo tanto la observación de la superficie del mar del área que cubren. Si la nubosidad no cubre una gran extensión, se puede estimar la TSM por interpolación (Pettigiani et al., 1992). Por otra parte, la bruma puede causar errores en la estimación de la TSM no siempre fáciles de detectar, ya que ésta contamina los pixeles haciendo bajar su valor. Para disminuir este tipo de errores, se efectúa una clasificación supervisada de las imágenes.

$\mathrm{Al}$ analizar la presencia de filamentos y remolinos, la nubosidad provoca una gran limitante, ya que estos fenómenos se producen a partir de las 30-40 y 
Tabla 6. Análisis de correlación múltiple (r) entre el Delta TSM, duración y extensión de los eventos de surgencia en la zona y período de estudio.

\begin{tabular}{|c|c|c|}
\hline & $\begin{array}{c}\text { Duración } \\
(\text { dias })\end{array}$ & $\begin{array}{c}\text { DeltaTSM } \\
\left({ }^{\circ} \mathrm{C}\right)\end{array}$ \\
\hline $\begin{array}{c}\text { Extensión } \\
(\mathrm{mn})\end{array}$ & $\begin{array}{c}0,1454^{*} \\
(0,165)^{* *}\end{array}$ & 0,3158 \\
\hline Duración & & 0,4023 \\
\hline
\end{tabular}

* : asociación no significativa

** : valor crítico

20-30 mn respectivamente, donde el porcentaje de imágenes sin interferencia de nubes es bajo (Fig. 1). Por este motivo, el estudio multitemporal de alta frecuencia de estos fenómenos a través de las imágenes de TSM se limitó al período de fines del verano hasta inicios del otoño, durante el cual se observaron remolinos (Tabla 3) y no obstante que los filamentos se observan durante todo el año. Cáceres (1992) estudió los filamentos y remolinos en la zona central de Chile y dio cuenta de la presencia de remolinos en los meses de enero, febrero, marzo, julio, octubre y diciembre de 1988. En el presente trabajo los filamentos se observan preferentemente en verano, pero no se puede concluir que sean exclusivos de este período del año. Esto puede deberse en parte, a que durante este período hay mayor disponibilidad de imágenes no afectadas por nubes en zonas alejadas de la costa.

Según Fonseca y Farías (1987), en las zonas de surgencia se produce generalmente nubosidad baja, de manera que disminuyen las oportunidades de observaciones satelitales utilizables. En el presente estudio se observó que al inicio de los fenómenos de surgencia la zona se encuentra normalmente sin nubosidad, pero después del tercer día ésta se puede hacer presente. Fonseca et al. (1987), encontraron un resultado similar al estudiar la surgencia de punta Curaumilla en la zona de Val paraíso $\left(33^{\circ} \mathrm{S}\right)$.

El análisis de las grillas para el cálculo de la proporción de nubes en la zona de estudio, permite apreciar que sobre el área de surgencia, en el borde de la plataforma, se registra la menor frecuencia de observaciones, lo que hace pensar que se trata de una zona de surgencia relativamente libre de dicha interferencia, similar a lo encontrado en un área de surgencia activa en el Atlántico Sudeste (Lutjeharms y Meeuwis, 1987).

Durante el período 1987-92 se observa una clara variabilidad de la TSM en la zona de estudio. En 1989, por ejemplo, se presenta el verano más frío del período y una primavera cálida (Figs. 2 y 3). Los inviernos de 1991 y 1988 son los más fríos del período, este último año habría manifestado condiciones tipificadas como La Niña (Philander, 1990). Cabe señalar que durante 1988 se observó el más alto porcentaje de días nublados. Las imágenes satelitales analizadas muestran una clara anomalía positiva, pero con diferentes características. En 1987 ésta se manifestó durante todo el año, mientras que en 1992 no se detectó en invierno. Cabe hacer notar que durante estos años se manifestaron en la zona de estudio los efectos del fenómeno El Niño, los cuales se consideraron de carácter moderado.

La surgencia de aguas frías es producto del accionar de vientos del S y SW en la superficie del mar. Cabe indicar que el viento implica una disminución de la temperatura, por lo tanto en las imágenes de TSM el indicador que se observa sería el de esta temperatura disminuída. En este sentido, Pizarro et al. (1994) muestran que una modificación del viento implica una perturbación en la temperatura.

En el presente trabajo se describen para la zona de estudio cinco focos de surgencia, que coinciden con los señalados por Fonseca y Farías (1987) en un primer trabajo efectuado sobre surgencia con sensoramiento remoto en dicha zona. La surgencia del sur de Iquique es la más importante por su extensión latitudinal, para esta zona se estima la más alta correlación entre el viento y la TSM. Esta zona de surgencia ha sido descrita por Brandhorst (1971) y Cañón (1978), quienes señalan que los eventos son más extensos, particularmente entre enero y marzo. La surgencia de Mejillones había sido descrita por Günther (1938) y Ulloa (1974), en el presente estudio se observa que ésta se presenta durante todo el año y es la única que tiene dirección hacia el norte.

Es interesante observar que los eventos de surgencia se presentan prácticamente durante todos los meses del período 1987-92 (Tabla 3). Pizarro et al. (1994) analizan los vientos de 1987-91 en las estaciones meteorológicas de Arica, Iquique y Antofagasta y concluyen que en las tres localidades el viento es favorable a la surgencia durante todo el año. Además, señalan que durante la temporada cá- 
Tabla 7. Análisis de correlaciones parciales entre zonas de surgencias, considerando la duración, intensidad, Delta TSM y extensión de los eventos de surgencias.

\begin{tabular}{|l|l|c|c|c|c|}
\hline a) & \multicolumn{1}{|c|}{ Zona } & $\mathrm{n}$ & $\begin{array}{c}\text { DeltaTSM } \\
\left({ }^{\circ} \mathrm{C}\right)\end{array}$ & $\begin{array}{c}\text { Extensión } \\
(\mathrm{mn})\end{array}$ & Intensidad \\
\hline Duración & Pta. Baquedano & 29 & 0,5926 & 0,1124 & 0,679 \\
(dias) & Pisagua & 25 & 0,6571 & $-0,4612$ & 0,825 \\
& Sur de Iquique & 23 & $-0,3948$ & $-0,6564$ & 0,890 \\
\hline
\end{tabular}

\begin{tabular}{|c|c|c|c|c|}
\hline b) & \multirow{2}{*}{ Años } & \multicolumn{3}{|c|}{ Intensidad } \\
\cline { 3 - 5 } & & Zona 1 & Zona 2 & Zona 3 \\
\hline \multirow{3}{*}{ Duración } & 1989 & $\begin{array}{c}0,902 \\
(0,582)\end{array}$ & $\begin{array}{c}0,879 \\
(0,621)\end{array}$ & $\begin{array}{c}0,929 \\
(0,521)\end{array}$ \\
\cline { 2 - 5 } & 1990 & $\begin{array}{c}0,817 \\
(0,412)\end{array}$ & $\begin{array}{c}0,5819 \\
(0,426)\end{array}$ & $\begin{array}{c}0,604 \\
(0,497)\end{array}$ \\
\cline { 2 - 5 } & 1991 & $\begin{array}{c}0,766 \\
(0,729)\end{array}$ & $\begin{array}{c}0,834 \\
(0,805)\end{array}$ & $0,770 *$ \\
\cline { 2 - 5 } & \multirow{2}{*}{190,} & &
\end{tabular}

* : asociación no significativa

( ) : valor crítico

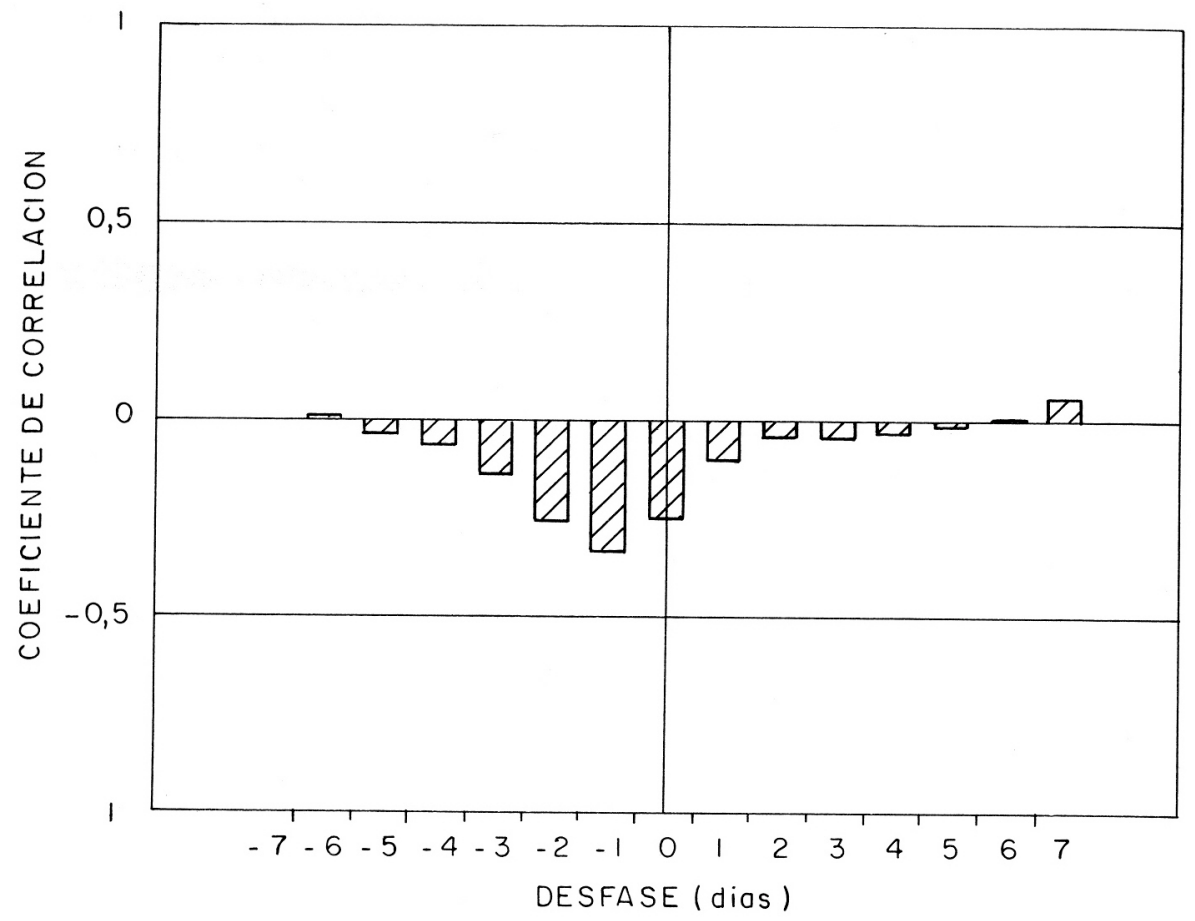

Figura 9. Correlaciones cruzadas entre los valores diarios del DeltaTSM de la zona de surgencia del sur de Iquique y el índice de Bakun en la estación meteorológica de Iquique (enero-abril de 1989). 


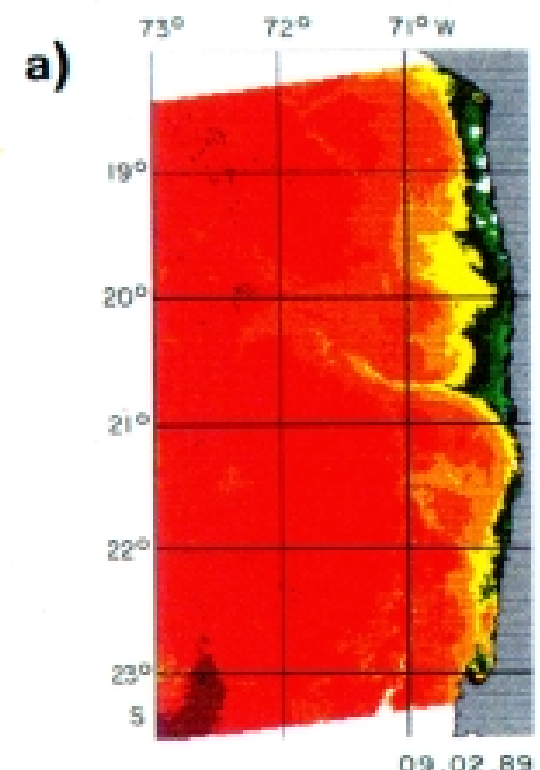

09.02 .89

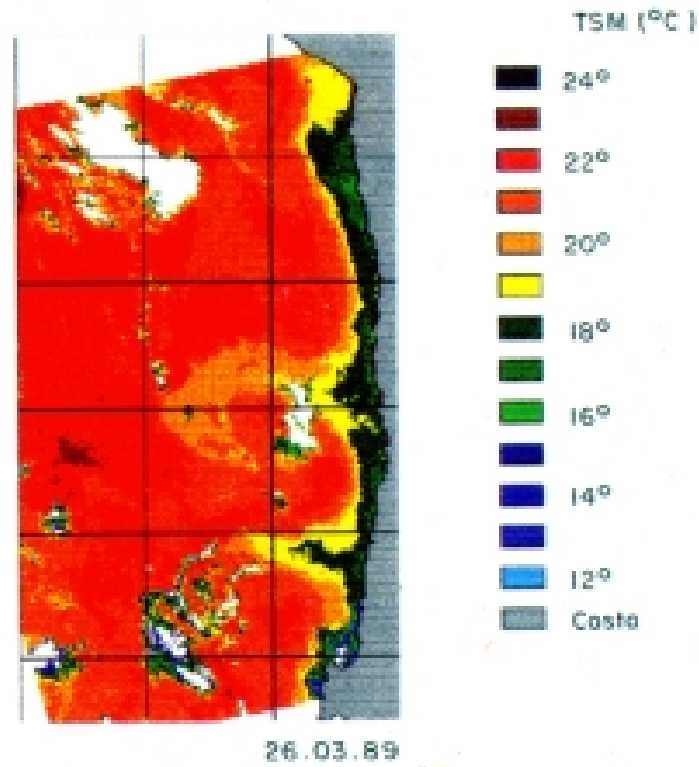

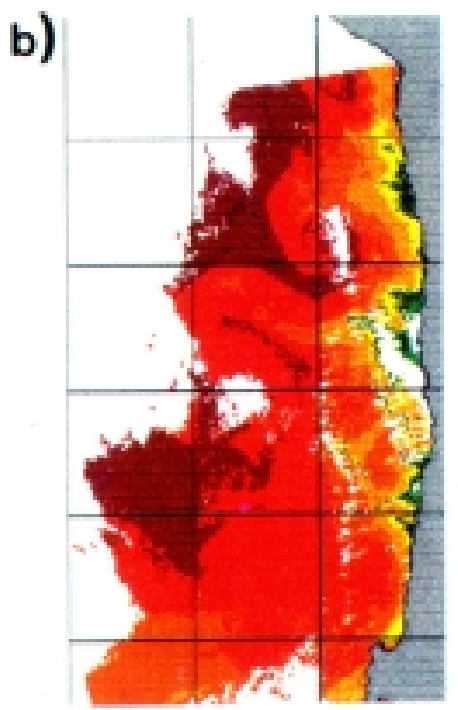

16.02 .88

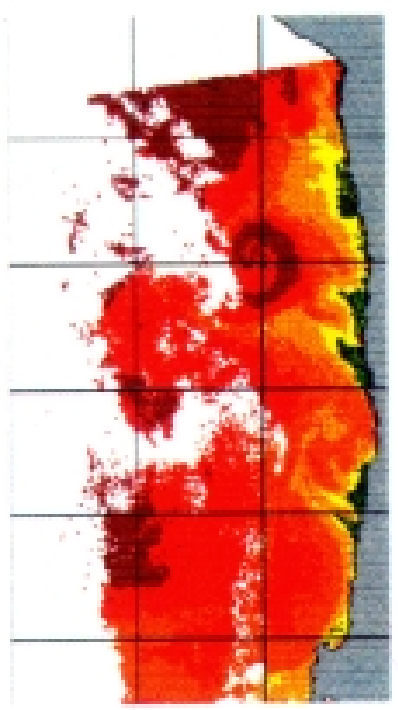

17.02 .88

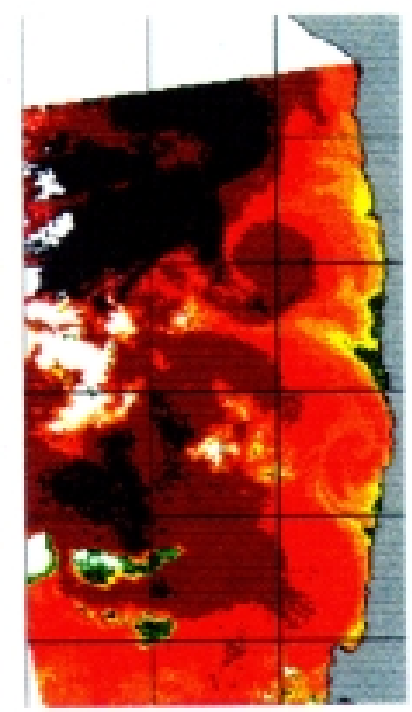

$18.02,88$

Figura 10. Imágenes satelitales de TSM: a) filamentos y b) remolinos. 
Tabla 8. Extensión (*) y dirección (**) de filamentos observados en imágenes satelitales de TSM.

\begin{tabular}{|c|c|c|c|c|c|c|c|c|c|c|c|}
\hline ZONA & AÑO & ENE & FEB & MAR & $\mathrm{ABR}$ & MAY & JUL & SEP & OCT & NOV & DIC \\
\hline Arica & $\begin{array}{l}88 \\
89 \\
90\end{array}$ & $\mathrm{M} / \mathrm{SW}$ & $\begin{array}{l}C / W \\
L / W\end{array}$ & L/SW & $\mathrm{M} / \mathrm{NW}$ & L & & & & $\begin{array}{l}\mathrm{C} / \mathrm{SW} \\
\mathrm{C} / \mathrm{W}\end{array}$ & L \\
\hline Pisagua & $\begin{array}{l}88 \\
89 \\
90\end{array}$ & $\begin{array}{l}\mathrm{M}-\mathrm{L} / \mathrm{W} \\
\mathrm{M} / \mathrm{W} \\
\mathrm{L} / \mathrm{NS}\end{array}$ & $\begin{array}{l}\mathrm{M} / \mathrm{W} \\
\mathrm{C} / \mathrm{W}\end{array}$ & $\begin{array}{l}\mathrm{M} / \mathrm{W} \\
\mathrm{C} / \mathrm{W}\end{array}$ & & & & $\mathrm{M} / \mathrm{NW}$ & & & C \\
\hline $\begin{array}{l}\text { Sur } \\
\text { de } \\
\text { Iquique }\end{array}$ & $\begin{array}{l}88 \\
89 \\
90\end{array}$ & LNNW & $\begin{array}{l}\mathrm{M} / \mathrm{NW} \\
\mathrm{L} / \mathrm{W}\end{array}$ & L/SW & $\mathrm{M} / \mathrm{SW}$ & LSW & & $\begin{array}{l}\mathrm{C} / \mathrm{NW} \\
\mathrm{L} / \mathrm{W}\end{array}$ & & $\begin{array}{l}\mathrm{C} / \mathrm{NW} \\
\mathrm{M} / \mathrm{NW} \\
\mathrm{M} / \mathrm{W}\end{array}$ & MNW \\
\hline $\begin{array}{l}\text { Punta } \\
\text { Lobos }\end{array}$ & $\begin{array}{l}88 \\
89 \\
90\end{array}$ & $\mathrm{M} / \mathrm{W}$ & & $\mathrm{M} / \mathrm{SW}$ & & & & & & & \\
\hline $\begin{array}{l}\text { Punta Arenas } \\
\text { y } \\
\text { Tocopilla }\end{array}$ & $\begin{array}{l}88 \\
89 \\
90\end{array}$ & $\begin{array}{l}\text { M-L/W } \\
\text { L-M/NW }\end{array}$ & $\begin{array}{l}\text { Remolino } \\
\mathrm{M} / \mathrm{NW} \\
\text { C/NW } \\
\mathrm{M} / \mathrm{W} \\
\mathrm{M} / \mathrm{NW}\end{array}$ & $\begin{array}{l}\text { LNW } \\
\text { M } \\
\text { LNW }\end{array}$ & LNW & & $\mathrm{M} / \mathrm{W}$ & $\mathrm{C} / \mathrm{W}$ & & $\mathrm{C} / \mathrm{W}$ & $\begin{array}{l}\text { C/W } \\
\text { M/NW } \\
\text { M-L/NW } \\
\text { M/W }\end{array}$ \\
\hline Mejillones & $\begin{array}{l}88 \\
89 \\
90\end{array}$ & $\begin{array}{l}\mathrm{M} / \mathrm{W} \\
\mathrm{L} / \mathrm{NW} \\
\mathrm{C} / \mathrm{NE}\end{array}$ & $\begin{array}{l}\text { C/W } \\
\text { M-LNWW } \\
\text { LN }\end{array}$ & $\begin{array}{l}\mathrm{C} / \mathrm{N} \\
\mathrm{M} / \mathrm{NW}\end{array}$ & MNW & $\begin{array}{l}\mathrm{L} \\
\mathrm{C} / \mathrm{W}\end{array}$ & & $\begin{array}{l}\text { C/NW } \\
\text { MNW }\end{array}$ & $\begin{array}{l}\mathrm{C} / \mathrm{NE} \\
\mathrm{M} / \mathrm{NW}\end{array}$ & $\begin{array}{l}\mathrm{C} / \mathrm{N} \\
\mathrm{M} / \mathrm{N}\end{array}$ & $\begin{array}{l}\text { C/NW } \\
\text { C/W } \\
\text { M/NW }\end{array}$ \\
\hline
\end{tabular}

*: $\quad \mathrm{L}=\mathrm{Larga}(>50 \mathrm{mn}) ; \mathrm{M}=$ Media $(50-30 \mathrm{mn}) ; \mathrm{C}=\mathrm{Corta}(<30 \mathrm{mn})$

**: $\mathrm{W}=$ oeste; $\mathrm{SW}=$ suroeste; $\mathrm{NW}=$ noroeste; $\mathrm{NE}=$ noreste; $\mathrm{NS}=$ norte-sur; $\mathrm{N}=$ norte

lida (noviembre a marzo) se presenta un viento continuo favorable a la surgencia con una varianza relativamente pequeña. En esta temporada las surgencias presentan una pluma más extensa que alcanza las $45 \mathrm{mn}$, con una moda de $35 \mathrm{mn}$ (Tabla $3)$. Por otra parte, en esta temporada la variación interanual de la extensión de la lengua surgente no es significativa $(\mathrm{p}>0,05)$, además se observan pocos períodos de relajamiento, o bien, éstos son de corta duración. En las Figs. 7a y 7b estos períodos están representados por la fase positiva de las señales diarias del DeltaTSM de las zonas de surgencia del período enero-abril. Pizarro et al. (1994) también señalan que durante la estación cálida casi no se observan eventos de vientos hacia el sur, mientras que durante los meses de invierno la predominancia de los vientos sigue siendo suroeste, pero con períodos de relajamiento especialmente en Iquique y Antofagasta. En esta época las surgencias presentan una longitud de la pluma de sólo $25 \mathrm{mn}$.

A diferencia de otras zonas del país, como las del centro y centro-sur, donde los eventos de surgencia sólo se presentan en primavera y verano (Cáceres y Arcos, 1991), en la zona norte éstos se presentan durante todo el año. Esto está relacionado con el predominio de los vientos del S, que producen una mezcla turbulenta en la zona de interfaz tierraaire y en la de surgencia de la zona costera. El viento de superficie tiene una componente del mar hacia la tierra y otra que refuerza el viento $S$, luego es un sistema retroalimentado positivamente, de los cuales depende la diferencia entre la TSM y la TST (temperatura superficial de la tierra). Considerando el viento costero, se produciría un forzamiento térmico (por la diferencia entre la TSM del mar y la TST del desierto) que conduciría a un alineamiento del viento con la costa, reforzando durante el día al viento $S$. También se debe considerar el efecto del viento de altura local.

Enfield (1981) muestra que la insolación sobre el desierto es la principal fuente de variabilidad en el forzante térmico. Montecinos (1991), en su estudio sobre los vientos favorables a la surgencia costera en 


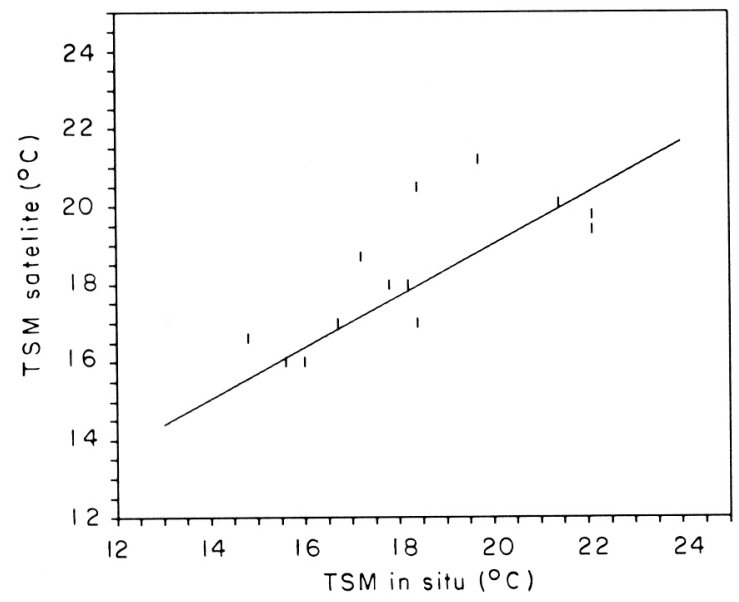

Figura 11. Asociación entre las TSM medidas in situ y la satelital $(\mathbf{r}=\mathbf{0 , 8 9})$.

el norte de Chile, encuentra resultados análogos. Los vientos predominantes del sur se presentan durante todo el año, aunque éste sea cálido o frío (Pizarro et al., 1994). En las cartas satelitales las surgencias se observan durante todo el período, pero al mismo tiempo se constata que existe variabilidad entre el número de eventos entre focos y entre años (Tabla 5). Sin embargo, al efectuar un ANDEVA a dos factores (años y focos), la diferencia entre los focos no es significativa (Fcal $>$ Ftabla, con $\mathrm{p}>0,05)$; resultados similares se estiman entre años, con excepción de 1990, que es diferente a los otros (Tabla 9). Estos resultados permiten señalar que en la zona de estudio se desarrollan eventos de surgencia durante todos los años, sean estos años El Niño, La Niña o años normales.

Los eventos de surgencia no se presentan en toda el área en forma simultánea entre los 8 focos. Esto puede deberse a que los vientos en Arica y Antofagasta alcanzan las máximas magnitudes desde fines de septiembre $y$, mientras que en Iquique se registran entre diciembre y marzo, justo en el período que se observan los remolinos en la zona de estudio (Pizarro et al., 1994). Existe un comportamiento más parecido en las surgencias que se producen entre Iquique y MejiIlones, que en las que se presentan al norte de Iquique. Esto se observa al comparar los picos negativos de las señales diarias del Delta TSM por foco de surgencia (Figs. 7a y 7b). Esto es particularmente notorio en 1992, cuando se manifiestan los efectos de un ENSO. Pizarro et al. (1994), indican que la composición espectral del viento es similar entre Iquique y Antofagasta, y existe coherencia significativa con máximos centrados entre 2,5 y 7 días, lo que explicaría el mayor sincronismo en esa área. Mientras que entre Iquique y Arica éste es menor, aunque la distancia entre ambos puntos sea más reducida, debido a que la coherencia entre los vientos es baja.

En la zona de Iquique, las correlaciones cruzadas entre la TSM y el índice de surgencia de Bakun indican significativos rezagos negativos, indicando una disminución de la TSM asociada al aumento de dicho índice (Fig. 9). Este índice de surgencia ha sido empleado en diversos estudios de relaciones de largo plazo entre condiciones ambientales y recursos pelágicos (Yáñez, 1991; Yáñez et al., 1992).

En cuanto a los filamentos, este estudio indica que se encuentran presentes en distintos períodos del año, y pueden tener diferentes longitudes y direcciones. Al igual que lo indicado por Cáceres (1992) para la zona central de Chile, en la zona norte los filamentos y remolinos se originan en deformaciones del frente de surgencia producidas por desviaciones del flujo principal de agua.

\section{CONCLUSIONES}

Las imágenes satelitales mostraron ser útiles para analizar la estructura térmica superficial del mar en la zona norte de Chile. A través de las imágenes disponibles del período 1987-92 se identificaron fenómenos de enfriamientos costeros que se presentan durante todo el año y que se alternan con períodos de relajamiento, además de filamentos y remolinos. Estos enfriamientos se manifiestan a través de surgencias costeras por focos (8) y franjas frías costeras, estas últimas se manifiestan principalmente en invierno e inicios de primavera.

Dichos focos permitieron identificar zonas de surgencias, las cuales se ubican geográficamente al sur de Anca $\left(18^{\circ} 35^{\prime} \mathrm{S}\right)$, frente a Pisagua $\left(19^{\circ} 35^{\prime} \mathrm{S}\right)$, al sur de Iquique $\left(20^{\circ} 31^{\prime}\right.$ a $\left.21^{\circ} 01^{\prime} \mathrm{S}\right)$, al norte de Tocopilla $\left(21^{\circ} 38^{\prime} \mathrm{S}\right)$ y frente a Mejillones $\left(23^{\circ} 02^{\prime} \mathrm{S}\right)$.

Durante el período de estudio se manifiestan en la zona los efectos de los fenómenos El Niño de 1987 y 1992, con anomalías positivas a nivel de la TSM de $1,5^{\circ}$ a $2^{\circ} \mathrm{C}$. Los eventos de surgencia se manifiestan a lo largo de todo el año. La variabilidad en cuanto al número de eventos de surgencia entre zo- 
Tabla 9. Comparación de medias del número de eventos de surgencia anuales en el período 1987-92.

\begin{tabular}{|c|c|c|c|c|c|c|}
\hline \multicolumn{2}{|c|}{ Años } & 1988 & 1989 & 1990 & 1991 & 1992 \\
\hline 1987 & $\begin{array}{l}a \\
b\end{array}$ & $\begin{array}{l}1,24 \\
0,38\end{array}$ & $\begin{array}{l}0,68 \\
1,14\end{array}$ & $\begin{array}{r}0,50^{* *} \\
-2,64^{* *}\end{array}$ & $\begin{array}{l}0,870 \\
0,630\end{array}$ & $\begin{array}{r}1,96 \\
-1,26\end{array}$ \\
\hline 1988 & $\begin{array}{l}a \\
b\end{array}$ & & $\begin{array}{l}0,55 \\
0,57\end{array}$ & $\begin{array}{c}0,40^{*} \\
-2,06^{*}\end{array}$ & $\begin{array}{l}0,669 \\
0,203\end{array}$ & $\begin{array}{r}1,58 \\
-1,50\end{array}$ \\
\hline 1989 & $\begin{array}{l}a \\
b\end{array}$ & & & $\begin{array}{c}0,72^{*} \\
-2,33^{*}\end{array}$ & $\begin{array}{r}1,20 \\
-0,35\end{array}$ & $\begin{array}{l}-0,45 \\
-1,85\end{array}$ \\
\hline 1990 & $\begin{array}{l}a \\
b\end{array}$ & & & & $\begin{array}{l}1,650 \\
2,090\end{array}$ & $\begin{array}{l}3,93 \\
1,09\end{array}$ \\
\hline 1991 & $\begin{array}{l}a \\
b\end{array}$ & & & & & $\begin{array}{r}2,37 \\
-1,54\end{array}$ \\
\hline
\end{tabular}

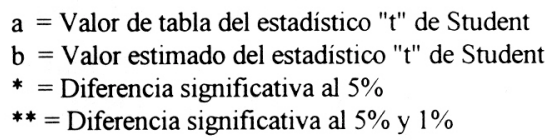

nas y años no es significativa, con excepción del año 1990.

La duración de los eventos de surgencia fluctúa entre 3 y 15 días, los eventos de mayor frecuencia duran entre 4 y 8 días. En la zona del sur de Iquique los eventos son de mayor duración, alcanzando los 15 días pero éstos corresponden a dos eventos consecutivos.

Las lenguas surgentes presentan normalmente una extensión de 30-40 mn en verano y de aproximadamente $25 \mathrm{mn}$ en invierno. Las lenguas muestran preferentemente una dirección NW y W, aunque en la zona de Mejillones ésta es normalmente N. El mayor gradiente de TSM es de $0,6{ }^{\circ} \mathrm{C} / \mathrm{mn}$.

Los eventos de surgencia no se presentan de manera simultánea en los distintos focos. Se observa un comportamiento análogo, pero con un cierto des fase, entre los focos de la zona al sur de Iquique y otro diferente entre los focos del norte de Iquique.

Se determina una asociación entre la variación de la TSM y la extensión y duración de los eventos de surgencia. Además, se determina con datos de la zona de Iquique una asociación, con un desfase de un día, entre la TSM filtrada y el índice de surgencia de Bakun.

Los filamentos se forman en los extremos de las lenguas surgentes, en las cinco zonas de surgencia y preferentemente, de noviembre a abril. Estos presentan un rango de longitud de 40-60 mn y direcciones NW y NWW; los de mayor longitud se observan frente a punta Lobos y punta Arenas, y pueden alcanzar las 100-120 mn de la costa. En la zona de Mejillones los filamentos son cortos, normalmente de dirección $\mathrm{N}$ y se presentan durante todo el año. Los remolinos son poco frecuentes y fueron observados entre diciembre y marzo.

\section{AGRADECIMIENTOS}

Los autores expresan sus agradecimientos a la Empresa Pesquera IGEMAR S.A. y en especial al Ing. Pesq. Guido Drago, por facilitar gran parte de la información satelital empleada en el presente trabajo. Además desean agradecer el aporte del Servicio Hidrográfico y Oceanográfico de la Armada y del Servicio Meteorológico de Chile, por proporcionar los datos de las estaciones de mareógrafos y meteorológicas de la zona de estudio. También expresan su reconocimiento al Centro Internacional de Investigaciones para el Desarrollo (CIID, Ottawa, Canadá) por el apoyo en el empleo de la teledetección. Finalmente agradecen a los revisores del trabajo, quienes efectuaron un valioso aporte anónimo. 


\section{REFERENCIAS BIBLIOGRAFICAS}

Acuña, E., J. Moraga y E. Uribe. 1989. La zona de Coquimbo: un sistema nerítico de surgencia de alta productividad. Pacífico Sur, Número Especial: $145-156$.

Bakun, A. 1973. Coastal upwelling indices, west coast of North America, 1946-71. U.S. Dep. Commer. NOAA Tech. Rep. NMFS-SSRF, 671, 103 pp.

Barbieri, M.A., F. Naranjo, E. Yáñez, M. Farías, G. Daneri y P. Rojas. 1987. La pesquería artesanal de atún aleta larga (Thunnus alalunga) en la zona de Valparaíso $\left(33^{\circ} \mathrm{S}-72^{\circ} \mathrm{W}\right)$ y el satélite NOAA. lnvest. Mar., Valparaíso, 15: 41-61.

Barbieri, M.A., E. Yáñez, M. Farías y R. Aguilera. 1989. Determination of probable fishing areas for the albacore (Thunnus alalunga) in Chile's central zone. In: «Quantitative Remote Sensing», IGARSS '89, Vancouver, Canadá, Vol. 4: $2447-$ 2450.

Brandhorst, W. 1971. Condiciones estivales frente a la costa de Chile. Rev. Biol. Mar., Valparaíso, 14 (3): 45-84.

Bravo, M. 1993. Estudio de los procesos de surgencia costera en el norte de Chile entre 1989 y 1990 (Arica a Antofagasta). Tesis, Escuela de Ciencias del Mar, UCV, 115 pp.

Cáceres, M. 1992. Vórtices y filamentos observados en imágenes de satelite frente al área de surgencia de Talcahuano, Chile Central. Invest. Pesq. (Chile), 37: 55-66.

Cáceres, M. y D. Arcos. 1991. Variabilidad en la estructura espacio-temporal de un área de surgencia frente a la costa de Concepción, Chile. lnvest. Pesq. (Chile), 36: 27-38.

Cañón, J.R. 1978. Distribución de la anchoveta (Engraulis ringens) en el norte de Chile en relación a determinadas condiciones oceanográficas. Serie lnvest. Pesq., IFOP, 30: 1-122.

Crépon, M., C. Richez y M. Chartier. 1984. Effects of coastline geometry on upwelling. Phys. Oceanogr. 14: 1365-1382.

Eastman, J.R.1992. IDRISI Version 4.1, User's Guide and Technical References. Clark University Graduate School of Geography, USA, 213 pp.
Enfield, D. 1981. Annual and non-seasonal variability of monthly low level wind fields over the Southeastem Tropical Pacifico Mon. Wea. Rev., 109: 2177-2190.

Espinoza, F., S. Neshyba y Z. Maoxiang. 1983. Surface water motion off Chile revealed in satellite images of surface chlorophyll and temperature. In: «Recursos Marinos del Pacífico», P. Arana (Ed.), Universidad Católica de Valparaíso, Oregon State University, U.S. Intemational Sea Grant Program y Universidad de Chile, 41-57.

Fonseca, T. y M. Farías. 1987. Estudio del proceso de surgencia en la costa chilena utilizando percepción remota. lnvest. Pesq. (Chile), 34: 33-46.

Fonseca, T., M.A. Barbieri, H. Olguín, S. Palma, N. Silva y M.I. Toledo. 1987. Eventos de surgencia en la zona de Valparaíso y sus efectos en el ecosistema marino. Proyecto FONDECYT $\mathrm{N}^{\circ} 1170 / 85$. Escuela de Ciencias del Mar, UCV, $75 \mathrm{pp}$.

Fuenzalida, H. 1971. Climatología de Chile. Departamento de Geofísica, Univ. de Chile, lnf. Int., $73 \mathrm{pp}$.

Fuenzalida, R. 1990. Variabilidad temporal de un índice de surgencia para la zoná de Iquique (Lat. $\left.20^{\circ} \mathrm{S}\right)$. Invest. Cient. y Tec., Serie Ciencias del Mar, 1: 37-47.

Günther, E. 1938. A report on oceanographical investigation in Perú coastal current. Discovery Rep., 13: 107-275.

Herbland, A. 1991. Quelques réflexions sur l'etude de l'environnement en vue d'analyser ses relations avec les ressorces. In: «Pêcheries Ouest Africaines: Variabilité, Instabilité et Changement». P. Cury et C. Roy (Eds.), Editions ORSTOM, París: 137-141.

Holland, J.A y X.H. Yan. 1992. Ocean thermal feature recognition, discrimination and tracking using infrared satellite imagery. IEEE, Trans. Geosc. Remote Sensing, 30 (5): 1046-1053.

Kudoh, J. y S. Noguchi. 1991. A study on threedimensional histogram of the NOAA AVHRR images. IEEE, Trans. Geosci. Remote Sensing, 29: 735-740.

Lutjeharms J.R.E. y J.M. Meeuwis. 1987. The extent and variability of South-East Atlantic upwelling. 
In: «The Benguela and comparable ecosystems», A.I.L. Payne, J.A. Gulland y K.H. Brink (Eds.). S. Afr. J. mar.Sci. 5: 51-62.

Mitchelson, G. 1993. Eddies in the Greenland Sea observed from infrared and visible satellite radiometry. OcéanologicaActa, 16 (3): 213-220.

Montecinos, A. 1991. Efecto del fenómeno El Niño en los vientos favorables a la surgencia costera en la zona norte de Chile. Tesis, Escuela Ciencias del Mar, UCV, 143 pp.

Pettigiani, E., H. Karszenbaum y M. Mejail. 1992. Análisis de imágenes satelitarias de temperaturas superficiales mediante funciones empíricas ortogonales en la zona común de pesca argentinouruguaya. Revista SELPER, 8(1): 4348 .

Philander, S.G. 1990. El Niño, La Niña and the Southern Oscillation. Inter. Geophysics Ser., Academic Press, USA, Vol. 46, 293 pp.

Pizarro, O., S. Hormazábal, A. González y E. Yáñez. 1994. Variabilidad del viento, nivel del mar y temperatura en la costa norte de Chile. Invest. Mar., Valparaíso, 22: 83-10 1.

Robles, F., E. Alarcón y A. Ulloa. 1976. Las masas de agua en la región norte de Chile y sus variaciones en un período frío (1967) y en períodos cálidos (1969,1971-1973). FAO, Fisheries Rep., 185: $94-196$

Rutllant, J. 1986. Interacción océano-atmósfera. Revista Geofísica. Inst. Panamer. de Geografía e Historia, 24: 173-189.

Strub, P., P. Kosro y A. Huyer. 1992. The nature of the filaments in the California Current System. J. Geophys. Res., 96: 14743-14768.

Recibido el 10 de mayo de 1995.

Aceptado ello de octubre de 1995.
Ulloa, A. 1974. Condiciones bio-oceanográficas de la agujilla Scomberesox equirostrum (Le Seur 1821). Tesis, Escuela de Pesquerías, UCV, 80 pp.

Van Camp, L., L. Nykjaer, E. Mittelstaedt y P. Schlittnhardt. 1991. Upwelling and boundary circulation off Northwest Africa as depicted by infrared and visible satellite observations. Prog. Oceanog., 26: 357-402.

Yáñez, E., M.A. Barbieri, A. González, O. Pizarro, M. Bravo, C. Canales y S. Salinas. 1994. Sea surface thermal structure associated to the pelagic fish resources distribution in northen Chile. In: «Remote Sensing for Marine and Coastal Environments: Needs, Solutions and Applications», ERIM, Michigan, USA, Vol. 11: 149-162.

Yáñez, E. 1991. Relationships between environmental changes and fluctuating major pelagic resources exploited in Chile (1950-1988). In: «Long-term variability of pelagic fish populations and their environment», T. Kawasaki et al. (Eds), Pergamon Press, 301-309.

Yáñez, E., Barbieri M. A. y L. Santillan. 1992. Longterm environmental variability and pelagic fisheries in Talcahuano, Chile. In: «Benguela Trophic Functioning», Payne, A.I.L., Brink, K.H., Mann, K.H. and R.Hiliborn (Eds). S. Afr. J. mar. Sci., 12: 175-188.

Yáñez, E., M.A. Barbieri y A. González. 1995. Estructura térmica superficial asociada a la distribución espacio-temporal de sardina y anchoveta en la zona norte de Chile entre 1987 y 1992 . Invest. Mar., Valparaíso, 23: 123-147. 